\title{
Polytopic Bis(oxazoline)-Based Ligands for the Development of Recoverable Catalytic Systems Applied to the Cyclopropanation Reaction
}

\author{
José I. García, *[a] Jaime Gracia, ${ }^{[a]}$ Clara I. Herrerías, *[a] José A. Mayoral, ${ }^{[a]}$ \\ Ana C. Miñana, ${ }^{[a]}$ and Carlos Sáenz ${ }^{[a]}$
}

\author{
Keywords: Coordination polymers / Copper / Polytopic ligands / Self-supported catalysts / Enantioselectivity / \\ Polymerization
}

\begin{abstract}
New ditopic and tetratopic chiral ligands, based on the bis(oxazoline) moiety, have been synthesized and their copper complexes tested as catalysts in the benchmark asymmetric cyclopropanation reaction of styrene with ethyl diazoacetate. The polytopic nature of these ligands enables a release-cap-
\end{abstract}

ture strategy to efficiently recycle the enantioselective catalyst by precipitation of a coordination polymer at the end of the reaction. This strategy enables the self-supported catalyst to be reused up to 20 times leading to good yields and enantioselectivities.

\section{Introduction}

Asymmetric catalysis is the most efficient method by which to obtain enantiomerically pure compounds. However, chiral catalysts are usually expensive and, in many cases, contain toxic metals. As a consequence, the easy separation of such catalysts from their reaction products in such a way as to avoid metal contamination, and their reuse in further catalytic runs, increasing their productivity, has become an interesting goal from both academic and industrial points of view. ${ }^{[1]}$ In recent years growing interest has focused on the recycling and reuse of enantioselective catalysts using a variety of strategies. ${ }^{[2-7]}$

Given the drawbacks usually associated with the use of chiral catalysts immobilized onto solid supports, an interesting alternative strategy involves carrying out the catalyzed reaction in homogeneous phase, and then selectively precipitating the catalyst, allowing its easy separation from the crude reaction and subsequent reuse in consecutive reactions. Several methods have been described to accomplish this goal. These include; a) linking of the chiral ligand to a soluble polymer, ${ }^{[5]}$ b) self-supporting the catalytic complex through intercatalyst hydrogen bonding, ${ }^{[8,9]}$ and c) coordination polymerization. ${ }^{[10,11]}$ In most cases, selective precipitation of the catalyst after the reaction is achieved by addition of a suitable solvent.

[a] Departamento de Catálisis y Procesos Catalíticos, Instituto de Síntesis Química y Catálisis Homogénea (ISQCH)

(CSIC-Universidad de Zaragoza),

50009 Zaragoza, Spain

E-mail: jig@unizar.es clarah@unizar.es

http://www.unizar.es
We recently described the synthesis of several ditopic (DAX, 2a and 2b) and tritopic (TAX, 3a and 3b) chiral ligands based on azabis(oxazoline), as well as a ditopic one bearing chiral bis(oxazoline) units ( $i$ PrDiBox) (2d) (Figure 1). These ligands were applied to the preparation of copper coordination polymers in order to promote a diversity of organic reactions in an enantioselective way, such as cyclopropanation of alkenes with ethyl diazoacetate, ${ }^{[12,13]}$ Henry or nitroaldol reactions, ${ }^{[14]}$ and Kharasch-Sosnovsky allylic oxidation of cycloalkenes with peroxo esters. ${ }^{[15,16]}$ The application of a release-capture strategy allowed selective precipitation of the polymers after reaction completion and product extraction by use of a non-coordinating solvent. The polymer could then be recovered and reused in subsequent reactions with good results.

This strategy has the additional advantages of not requiring chemical modification of the chiral ligand (simplifying its synthesis and avoiding possible erosion of enantioselective capability) and of circumventing the use of an additional support since the coordination polymer is self-supporting.

In this work, we report the use of several monotopic, ditopic and tetratopic bis(oxazoline)- and azabis(oxazoline)-based ligands (Figure 1), including the three new ditopic ligands $t$ BuDiBox (2c), PhDiBox (2e) and InDiBox (2f) and two new tetratopic ligands click-tBuQAX (4a) and click-iPrQAX (4b) for the preparation of copper complexes that are subsequently used as homogeneous catalysts in the cyclopropanation of styrene with ethyl diazoacetate (Scheme 1), the benchmark representative for cyclopropanation chemistry. Copper complexes can then be separated from the reaction medium by precipitation of the corresponding coordination polymers $\left[\left(\mathrm{L}^{*} \mathrm{Cu} \mathrm{X}_{2}\right)_{n}\right]$ at the end of the reaction. 


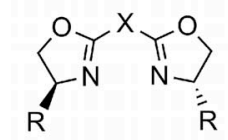

1a: $X=N M e ; R=t B u$ 1b: $X=\mathrm{NMe} ; \mathrm{R}=i \mathrm{Pr}$

1c: $X=\mathrm{CMe}_{2} ; R=t \mathrm{Bu}$

1d: $\mathrm{X}=\mathrm{CMe}_{2} ; \mathrm{R}=i \mathrm{Pr}$

1e: $\mathrm{X}=\mathrm{CMe}_{2} ; \mathrm{R}=\mathrm{Ph}$

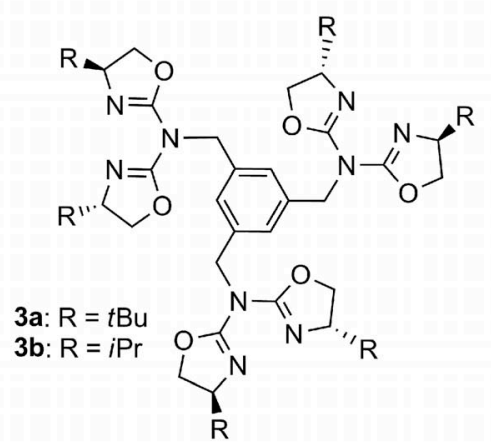

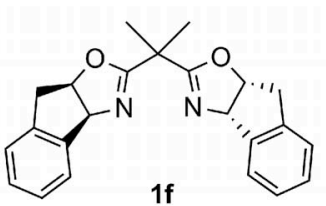

$\sum_{0}^{R_{1}}$

2a: $X=N M e ; R=t B u$

2b: $X=\mathrm{NMe} ; \mathrm{R}=i \mathrm{Pr}$

2c: $X=\mathrm{CMe}_{2} ; \mathrm{R}=t \mathrm{Bu}$

2d: $\mathrm{X}=\mathrm{CMe}_{2} ; \mathrm{R}=i \mathrm{Pr}$

1e: $\mathrm{X}=\mathrm{CMe}_{2} ; \mathrm{R}=\mathrm{Ph}$

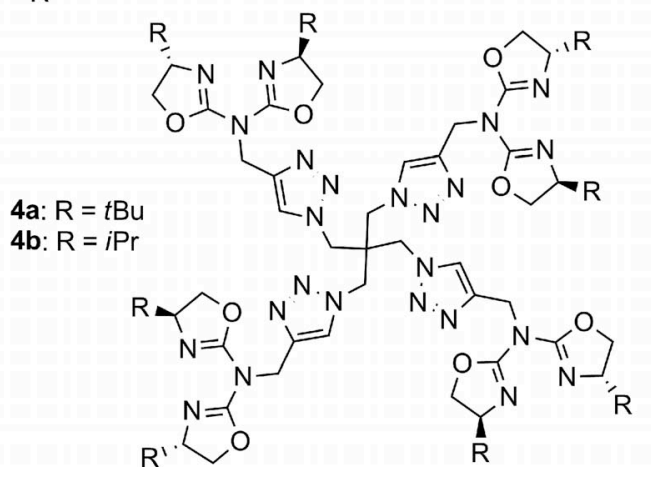

Figure 1. Structures of the different monotopic and polytopic chiral ligands.

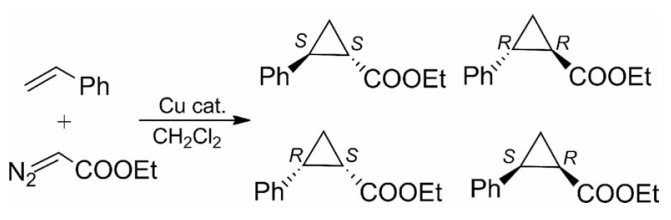

Scheme 1. Cyclopropanation reaction between styrene and ethyl diazoacetate.

\section{Results and Discussion}

\section{Design and Synthesis of the Ligands}

We started our study by synthesizing new polytopic ligands based on bis(oxazoline) and azabis(oxazoline) moieties. In the context of DiBox ligands, the synthesis of $i$ PrDiBox (2d) had been previously reported by our group $;^{[14]}$ similar synthetic schemes were applied for the preparation of corresponding $t \mathrm{BuDiBox}$ (2c), PhDiBox (2e) and InDiBox (2f). These ligands were prepared by condensation of two moieties of the corresponding bis(oxazoline), following deprotonation with one equivalent of $t \mathrm{BuOK}$ and subjection to $\alpha, \alpha^{\prime}$-dibromo- $p$-xylene (Scheme 2).
Alternatively, ligands 4, referred to as click-QAX, were obtained following a click chemistry synthetic strategy already established in our group for the synthesis of clickDAX ditopic ligands. ${ }^{[13]}$ A similar strategy has been applied to link azabis(oxazolines) to polymeric, dendrimeric, and inorganic supports. ${ }^{[17-20]}$ Copper-catalyzed [3 + 2] cycloaddition $^{[21-23]}$ between 5 and 0.25 equiv. of 1,3-diazido-2,2bis(azidomethyl)propane afforded $\mathbf{4}$ in good yield (Scheme 2). Complete characterization data for these new ligands prepared for this work are available in the Supporting Information.

It is worth mentioning that the synthesis of all these polytopic ligands was very efficient and that the synthetic effort required for their preparation is equivalent to that needed for the preparation of their counterpart monotopic ligands used in traditional homogeneous catalysis.

\section{Formation of the Coordination Polymers}

For the preparation of the coordination polymer, copper was used both as the point of ligand connection and as the catalytically active metal. Specifically $\mathrm{Cu}(\mathrm{OTf})_{2}$ was chosen since this copper salt has provided excellent results in the 


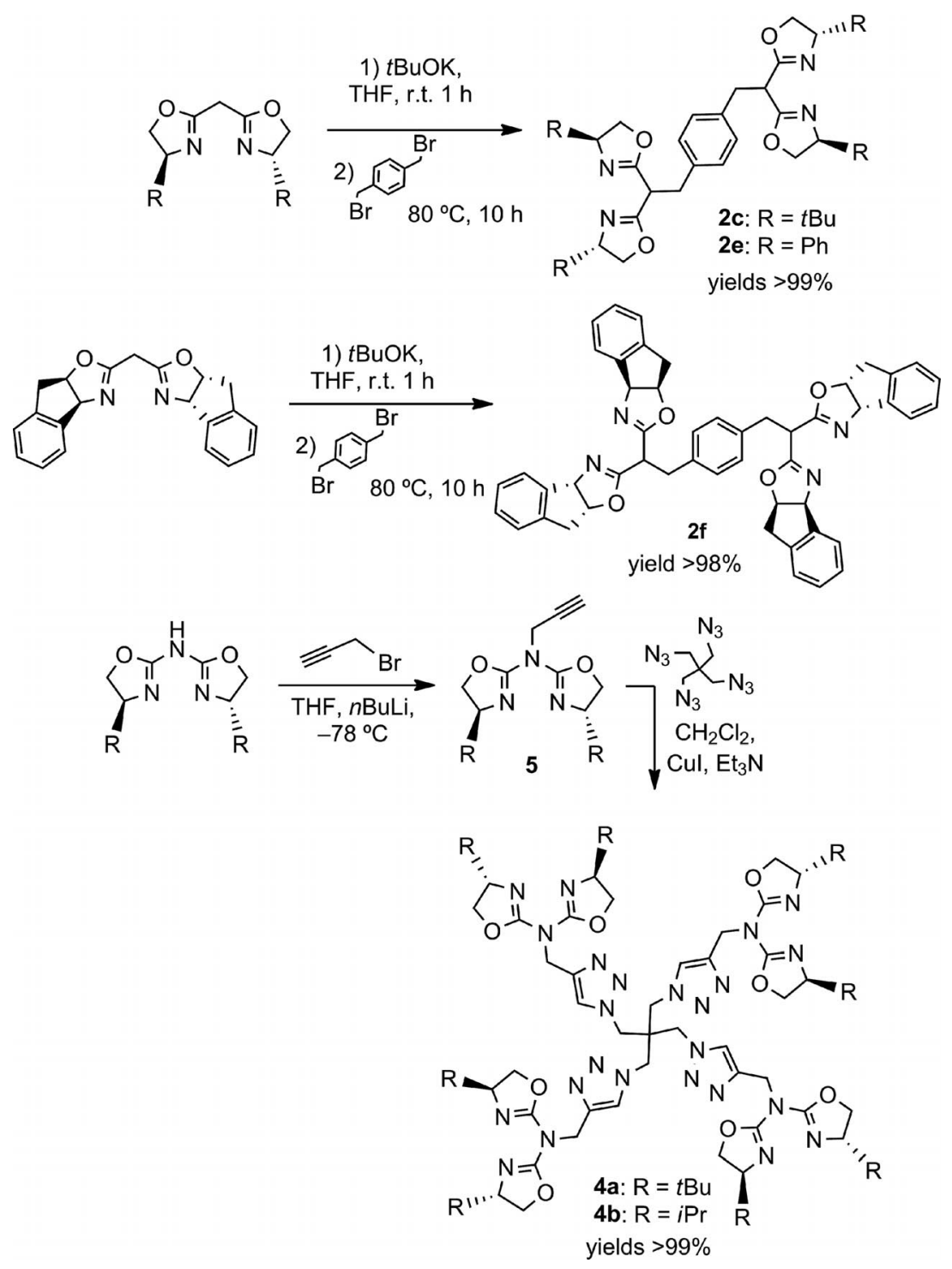

Scheme 2. Synthesis of the different polytopic ligands: DiBox y click-QAX.

cyclopropanation reaction between styrene and ethyl diazoacetate. In this sense, the low coordinating ability of the triflate anion fulfills two important requirements. First of all, it enables access to enantioselectivities higher than those obtained with coordinating anions, such as chloride. ${ }^{[24,25]}$ Secondly, the use of a weak counter anion favors the simultaneous coordination of two bis(oxazoline) or azabis(oxazoline) moieties to one copper ion thereby enabling formation of the coordination polymer at the end of the reaction. Other copper salts with a strong coordinating counterion, such as $\mathrm{CuCl}$, prevent recruitment of two azaBox ligands by copper since the chloride anions remain within the copper coordination sphere thereby restricting formation of the coordination polymer and the possibility of catalyst recovery. ${ }^{[12]}$

We found that coordination polymers were formed by mixing the corresponding polytopic bis(oxazoline) ligands 2 or 4 with copper triflate salts in the appropriate $\mathrm{Cu} / \mathrm{L}$ molar ratio in $\mathrm{CH}_{2} \mathrm{Cl}_{2}$. The appropriate $\mathrm{L} / \mathrm{Cu}$ molar ratio was found to be different when forming the polymer with DiBox ligands (2) or with click-QAX (4). In the first case, a 1:1 molar ratio was found to be optimal. When working with click-QAX, the optimal ratio for polymer induction was found to be 1:2 because of the four coordination sites per ligand (Figure 2). A greater than optimal amount of copper in the reaction medium favored formation of shorter polymers and monomers, thereby complicating catalyst recovery by precipitation.

\section{Structural Studies of the Catalysts by FESEM}

One of the most important features of a catalyst is its structure given that both catalytic performance and recoverability are dictated by structural characteristics. X-ray diffraction techniques have been profusely employed in the characterization of catalytic metal complexes. Disappointingly, copper complexes involving polytopic ligands $\mathbf{2}$ and 
a)

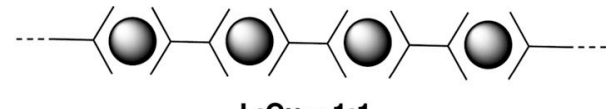

$\mathrm{L}: \mathrm{Cu}=1: 1$

b)

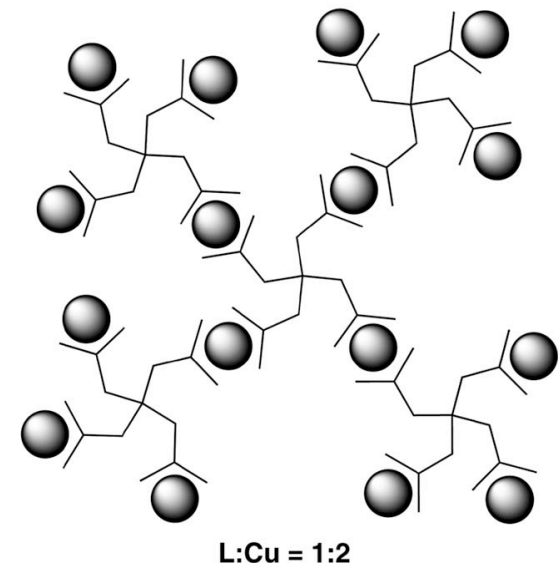

Figure 2. Schematic representation of the self-assembled catalysts from the coordination of copper cations with: a) DiBox ligands (chains) and b) click-QAX ligands (3D structures).

even 4 proved recalcitrant to crystallization techniques despite having tried several crystallization techniques. Diffraction quality crystals for these complexes remain elusive though efforts to obtain crystallographic data on any member of this catalyst class remains a high priority for our group.

Indirect techniques to elucidate coordination polymer structures had previously proven successful in our research group with metal complexes of $\mathbf{2 a}(t \mathrm{BuDAX})$ and $\mathbf{2 b}$ $(i \operatorname{PrDAX}) .{ }^{1} \mathrm{H}$ NMR DOSY ${ }^{[26,27]}$ experiments had been carried out using $\mathrm{Cu}^{\mathrm{I}}$ and $\mathrm{Zn}^{\mathrm{II}}$ complexes of $i \operatorname{PrDAX}$ and similar DOSY experiments have been successfully applied to the study of the size of molecular aggregates, metal-1igand complexes, and metallosupramolecular architectures in solution. ${ }^{[28-31]}$ Some experiments were done using the complex of $\mathrm{Zn}(\mathrm{OTf})_{2}$ with the monotopic ligand, and the corresponding complexes with ditopic ligand in different stoichiometries. When the $\mathrm{Zn} / \mathbf{2} \mathbf{b}$ ratio was adjusted to $1: 1$ (the ideal stoichiometry for formation of a coordination polymer), minimized diffusion coefficients were observed indicating the presence of oligomeric species. ${ }^{[15]}$

To collect more information on the copper coordination polymers, analyses were conducted using high-resolution mass spectrometry (HRMS). These experiments were carried out with the complex $\mathrm{Cu}^{\mathrm{I}}(\mathrm{OTf})-\mathbf{2 a}$. HRMS revealed the formation, in the gas phase, of $[\mathrm{Cu}-\mathbf{2} \mathbf{a}]_{\mathrm{n}}{ }^{\mathrm{n}+}$ species $(n=$ $1-3)$, as well as other oligomeric species with three and four copper atoms linked to four or three ditopic ligands, respectively. ${ }^{[13]}$ These results strongly support the hypothesis that the complexes formed in a non-coordinating solvent are indeed coordination polymers.

In the case of the $\mathrm{Cu}$-ditopic ligand complexes we propose the formation of a linear polymer structure. Since no single crystal of these complexes could be obtained, we decided to study the solids formed using Field Emission Scan- ning Electron Microscopy (FESEM). In the corresponding micrographs the presence of fibers with a hierarchical structure is clearly observed (Figure 3). The fibrous microscopic structure may reflect the molecular arrangement of ligand and metal under the form of a linear coordination polymer.

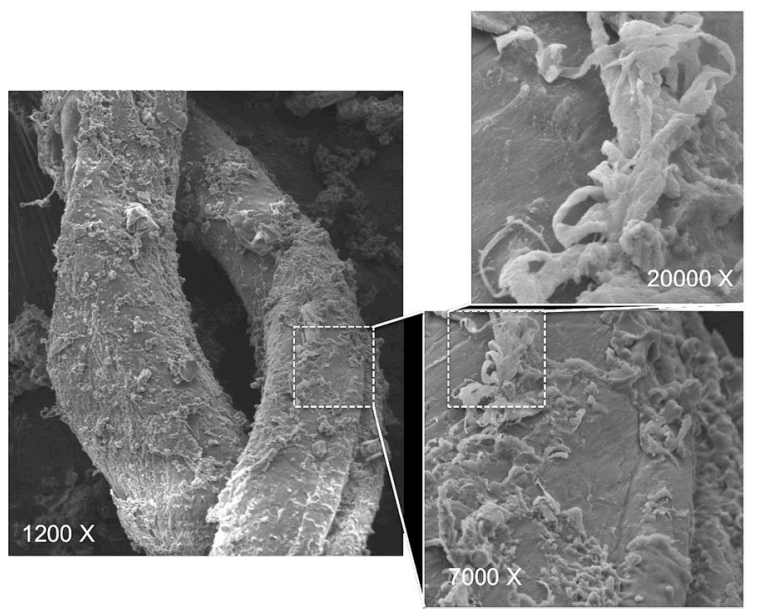

Figure 3. FESEM micrograph of the $i \operatorname{PrDiBox}-\mathrm{Cu}(\mathrm{OTf})_{2}[\mathbf{2 d}-\mathrm{Cu}]_{n}$ complex in solid phase.

\section{Self-Supported Catalysts: Mode of Use}

Coordination polymers are attractive for applications in catalysis since they combine the beneficial attributes of both homogeneous and heterogeneous catalysis. During the reaction, the polymer disassembles due to competitive coordination of either the reactants or the reaction solvent and the resulting monomeric metal complexes become soluble thus allowing for the kinds of excellent results often associated with traditional homogeneous complexes. Upon completion of the catalytic reaction, a simple change in solvent can trigger reassembly of the coordination polymer and subsequent precipitation. The resulting heterogeneous selfsupported catalyst in its resting state, is easily recoverable by decanting or other simple liquid/solid separation techniques.

This concept is demonstrated in the copper-catalyzed cyclopropanation of styrene with ethyl diazoacetate (Scheme 1). All the coordination polymers prepared for this work with polytopic ligands 2 or $\mathbf{4}$ and $\mathrm{Cu}(\mathrm{OTf})_{2}$ in a $1: 1$ or 1:2 molar ratio, are insoluble in $\mathrm{CH}_{2} \mathrm{Cl}_{2}$ (reaction solvent), but they are disassembled and hence solubilized, in the presence of ethyl diazoacetate. Driving this solubilization is the formation of copper carbenoid complexes, which are known to be decisive intermediates in the title reaction. ${ }^{[32-36]}$ As a result, the catalytically active monomeric copper-ligand species are released and the cyclopropanation reaction proceeds in the homogeneous phase with yields and enantioselectivities similar to those described with the monotopic copper-bis(oxazoline) catalysts.

After consumption of the ethyl diazoacetate the polymer reassembles. Although in the first reaction cycle the polymer formation occurs in a short period of time, in the fol- 
lowing cycles it takes more time due to the presence of byproducts. Therefore, the procedure for catalyst recovery was optimized. Catalyst recovery consists of evaporating most of the $\mathrm{CH}_{2} \mathrm{Cl}_{2}$ and extracting the reaction products with $n$ hexane, in which the coordination polymer is nearly insoluble. Following $n$-hexane extractions, a fine green powder appears at the bottom of the reaction vessel. After centrifugation, it is possible to decant the solvent where the products, byproducts and residual starting materials are dissolved. After drying the catalyst with argon, it can be reused in consecutive reaction cycles by adding again $\mathrm{CH}_{2} \mathrm{Cl}_{2}$, styrene and ethyl diazoacetate.

\section{Catalytic Studies}

To explore the self-supporting catalytic possibilities of new DiBox and click-QAX ligands, we used their corresponding $\mathrm{Cu}(\mathrm{OTf})_{2}$ complexes in the benchmark asymmetric cyclopropanation reaction of styrene with ethyl diazoacetate because of the huge amount of previous data available for this reaction.

For the sake of comparison we first studied the conventional homogeneous reactions. Table 1 gathers the results obtained in the cyclopropanation reaction catalyzed by complexes of the monotopic bis(oxazoline) and azabis(oxazoline) ligands with $\mathrm{Cu}(\mathrm{OTf})_{2}$.

Table 1. Cyclopropanation reactions between styrene and ethyl diazoacetate catalyzed by $\mathrm{Cu}-\mathrm{L} .^{[\mathrm{a}]}$

\begin{tabular}{llccc}
\hline Entry & Ligand & Yield [\%] & \% ee trans & $\%$ ee cis \\
\hline 1 & $t$ BuBox (1c) & 72 & 94 & 91 \\
2 & $i \operatorname{PrBox}(\mathbf{1 d})$ & 53 & 72 & 63 \\
3 & PhBox (1e) & 33 & 54 & 42 \\
4 & InBox (1f) & 86 & 76 & 78 \\
5 & $t$ BuAzaBox(1a) & 82 & 92 & 84 \\
6 & $i \operatorname{PrAzaBox(1b)}$ & 45 & 74 & 57
\end{tabular}

[a] Reagents and conditions: styrene ( 1 equiv.), ethyl diazoacetate (1 equiv.), $\mathrm{L}-\mathrm{Cu}(\mathrm{OTf})_{2}(1 \mathrm{~mol}-\%), \mathrm{CH}_{2} \mathrm{Cl}_{2}$, room temperature, yield and selectivities were determined by gas chromatography (methyl silicone and Cyclodex- $\beta$ columns). (1R,2R)-trans-cyclopropane and $(1 R, 2 S)$-cis-cyclopropane are the major isomers. The trans/cis ratio is ca. 70:30 in all cases.

As can be seen, high yields and enantioselectivities are obtained when the chiral ligands display tert-butyl substituents. It can be also observed that, in almost all cases, the enantioselectivities for trans-cyclopropanes are slightly better than those for the cis products.

It is worth noting that in all reactions a 1:1 styrene:ethyl diazoacetate molar ratio was used leading to low yields in some cases; the likely cause of this observation is competitive dimerization of the diazo-compound. Even so, good yields are obtained with the complexes of those ligands bearing tert-butyl and indanyl substituents. Of course, these yields could be further improved by increasing the olefin:diazo compound ratio, as is often done in synthetically-oriented works.
Next, we evaluated the behavior of ditopic ligands based on bis(oxazolines), referred to as DiBox. We started with the $t$ BuDiBox ligand, and results obtained with the corresponding copper complex are gathered in Table 2 .

Table 2. Cyclopropanation reactions between styrene and ethyl diazoacetate catalyzed by $\mathrm{Cu}-t \mathrm{BuBox}$ and $\mathrm{Cu}-t \mathrm{BuDiBox} .^{[\mathrm{a}]}$

\begin{tabular}{llccccc}
\hline Entry & \multicolumn{1}{c}{ Ligand } & Run & $\begin{array}{c}\text { Yield } \\
{[\%]}\end{array}$ & trans/cis & $\begin{array}{c}\% \text { ee } \\
\text { trans }\end{array}$ & $\begin{array}{c}\% \text { ee } \\
\text { cis }\end{array}$ \\
\hline 1 & $t$ BuBox (1c) & - & 72 & $71: 29$ & 94 & 91 \\
$2^{[\mathrm{b}]}$ & $t$ BuBox-2Bn (6a) & - & 46 & $33: 67$ & 70 & 79 \\
3 & $t$ BuDiBox (2c) & 1 & 82 & $36: 64$ & 70 & 70 \\
4 & & 2 & 75 & $35: 65$ & 70 & 71 \\
5 & & 3 & 77 & $35: 65$ & 71 & 70 \\
6 & & 4 & 52 & $36: 64$ & 69 & 70 \\
7 & 5 & 58 & $36: 64$ & 72 & 71 \\
8 & 6 & 65 & $37: 63$ & 69 & 70 \\
9 & 7 & 62 & $39: 61$ & 68 & 70 \\
10 & 8 & 57 & $40: 60$ & 68 & 69 \\
11 & 9 & 55 & $40: 60$ & 69 & 70 \\
12 & & 68 & $41: 59$ & 65 & 68 \\
\hline
\end{tabular}

[a] Reagents and conditions: styrene (1 equiv.), ethyl diazoacetate (1 equiv.), $\mathrm{L}-\mathrm{Cu}(\mathrm{OTf})_{2}(1 \mathrm{~mol}-\%), \mathrm{CH}_{2} \mathrm{Cl}_{2}$, room temperature, yield and selectivities were determined by gas chromatography (methyl silicone and cyclodex- $\beta$ columns). (1R,2R)-trans-cyclopropane and $(1 R, 2 S)$-cis-cyclopropane are the major isomers. [b] Taken from ref. ${ }^{[37]}$

The most pronounced and noteworthy trend displayed by these results is the diastereoselectivity inversion. When the complex with monotopic ligand 1c was used as catalyst, trans-cyclopropanes were the major isomers generated (Table 2, Entry 1). However, when using the $t \mathrm{BuDiBox}-\mathrm{Cu}$ complex, cis-cyclopropanes constituted the predominant products generated. This inversion of diastereoselectivity has been previously observed in our group using homogeneous catalyst $\mathrm{Cu}-t \mathrm{BuBox}$ (6a) which contains two benzyl units in the bridge (Figure 4). ${ }^{[37]}$

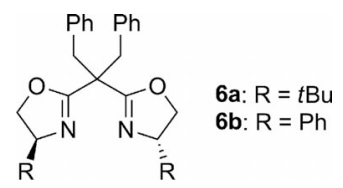

Figure 4. Structures of $t$ BuBox-2Bn (6a) and PhBox-2Bn (6b).

It is clear that the presence of the benzyl group modifies the geometry of the catalytic intermediate and this is reflected by the results in Table 2. This not only impacts trans/cis selectivity; the enantioselectivity obtained with $\mathrm{Cu}-$ $t$ BuDiBox complex more closely resembles that obtained with the complex with ligand $\mathbf{6 a}$ than that with ligand $\mathbf{1 c}$.

The coordination polymer with $\mathrm{Cu}-t \mathrm{BuDiBox}$ can be recovered during at least 10 runs and recovered catalyst was found capable of delivering results that are on par with the first cycle (Table 2, Entries 3-12). Erratic reaction yields were observed along the recycling experiments though these could be attributed to incomplete product extractions with hexane after some of the reactions. These products are envisioned to possibly accumulate in the reaction medium and, 
subsequently, can be extracted in a successive run. The influence of this particular behavior on yields was also observed in experiments with all the other coordination polymers used in this work. Some tests sought to increase the number of times that catalyst was washed, so as to improve the product extraction methodology. The problem was that, if the catalyst was washed more than three times, not only the products and by-products are extracted but part of the polymer is also dissolved. Thus, it became necessary to reach a compromise between properly cleaning up catalyst versus inadvertently inducing its loss during the extraction process. Even so, the yields in all reaction cycles were found to be superior to those obtained with complex $\mathrm{Cu}-6 \mathbf{6}$.

Afterwards, $\mathrm{Cu}-i$ PrDiBox was also used as the catalyst in the cyclopropanation reaction; the results are shown in Table 3.

Table 3. Cyclopropanation reactions between styrene and ethyl diazoacetate catalyzed by $\mathrm{Cu}-i \operatorname{PrBox}$ and $\mathrm{Cu}-i \operatorname{PrDiBox} .{ }^{[a]}$

\begin{tabular}{llccccc}
\hline Entry & Ligand & Run & $\begin{array}{c}\text { Yield } \\
{[\%]}\end{array}$ & trans/cis & $\begin{array}{c}\% \text { ee } \\
\text { trans }\end{array}$ & $\begin{array}{c}\% \text { ee } \\
\text { cis }\end{array}$ \\
\hline 1 & $i$ PrBox (1d) & - & 53 & $70: 30$ & 72 & 63 \\
2 & $i$ PrDiBox (2d) & 1 & 39 & $57: 43$ & 59 & 61 \\
3 & & 2 & 35 & $57: 43$ & 62 & 63 \\
4 & & 3 & 49 & $54: 46$ & 63 & 63 \\
5 & & 4 & 41 & $52: 48$ & 62 & 62 \\
6 & 5 & 47 & $52: 48$ & 61 & 60 \\
7 & 6 & 41 & $51: 49$ & 62 & 60 \\
8 & 7 & 45 & $52: 48$ & 62 & 60 \\
9 & 8 & 39 & $53: 47$ & 62 & 61 \\
10 & 9 & 39 & $52: 48$ & 63 & 63 \\
11 & & 28 & $50: 50$ & 60 & 62 \\
\hline
\end{tabular}

[a] Reagents and conditions: styrene (1 equiv.), ethyl diazoacetate (1 equiv.), $\mathrm{L}-\mathrm{Cu}(\mathrm{OTf})_{2}(1 \mathrm{~mol}-\%), \mathrm{CH}_{2} \mathrm{Cl}_{2}$, room temperature, yield and selectivities were determined by gas chromatography (methyl silicone and cyclodex- $\beta$ columns). (1R,2R)-trans-cyclopropane and $(1 R, 2 S)$-cis-cyclopropane are the major isomers.

In this case, there was no apparent inversion in the trans/cis ratio when we consider the complex with the ditopic ligand. However, a loss of diastereoselectivity was observed (from 70:30 to 55:45). This effect could be attributed to the benzyl group present in the DiBox ligand as was the case for $t$ BuDiBox (2c). However, the enantioselectivities obtained using $\mathrm{Cu}-i \operatorname{PrDiB}$ ox complex were the same as with the $\mathrm{Cu}-i \operatorname{PrB}$ ox complex, especially in the case of the cis-isomers. This indicates that the benzyl effect, in this case, is not as influential as that observed in Table 2.

Recovery of the catalyst in this case was excellent, yields were moderated in all cases due to the chemoselectivity of the reaction, as we have described above. However, observed enantioselectivities were as good as those obtained with the monotopic liganded complex. The quality of reaction results with $\mathrm{Cu}-i \operatorname{PrDiBox}$ was easily retained over the course of 10 runs, as anticipated.

On the other hand, when complexes with phenyl-substituted ligands were used $(\mathrm{Cu}-\mathbf{1 e}, \mathrm{Cu}-\mathbf{2 e}$ and $\mathrm{Cu}-\mathbf{6 b})$, results were found to be moderated (Table 4). Not only yields, but also ee values for both diastereomers were found to be less than $60 \%$. Despite these poor results, the recovery of cata- lyst $\mathrm{Cu}-\mathrm{PhDiBox}$ (2e) was found to effective enabling acquisition of the same values with $\mathrm{Cu}-\mathbf{1 e}$ and $\mathrm{Cu}-\mathbf{6 b}$ complexes over the course of 10 cycles. Curiously, in this case, the effect of the benzyl group in the bridge was negligible, only small changes in diastereoselectivity were observed, from a value of 70:30 with ligands $\mathbf{1 e}$ or $\mathbf{6 b}$, to a value of 65:35 in the case of 2e. Even the enantioselectivity obtained with complex 2e, which included the ditopic ligand, was found to be slightly better than that obtained with homologous complexes, in contrast to the behavior of complexes $\mathbf{2 c}$ and 2d.

Table 4. Cyclopropanation reactions between styrene and ethyl diazoacetate catalyzed by $\mathrm{Cu}-\mathrm{PhBox}$ and $\mathrm{Cu}-\mathrm{PhDiBox} .{ }^{[a]}$

\begin{tabular}{llccccc}
\hline Entry & \multicolumn{1}{c}{ Ligand } & $\begin{array}{c}\text { Run } \\
\text { Yield } \\
{[\%]}\end{array}$ & trans/cis & $\begin{array}{c}\% \text { ee } \\
\text { trans }\end{array}$ & $\begin{array}{c}\% \text { ee } \\
\text { cis }\end{array}$ \\
\hline 1 & PhBox (1e) & - & 33 & $71: 29$ & 54 & 42 \\
$2^{[b]}$ & PhBox-2Bn (6b) & - & 32 & $70: 30$ & 50 & 40 \\
3 & PhDiBox (2e) & 1 & 38 & $69: 31$ & 60 & 45 \\
4 & & 2 & 44 & $66: 34$ & 63 & 50 \\
5 & 3 & 42 & $65: 35$ & 62 & 50 \\
6 & 4 & 52 & $64: 36$ & 58 & 51 \\
7 & 5 & 50 & $64: 36$ & 58 & 53 \\
8 & 6 & 32 & $64: 36$ & 58 & 54 \\
9 & 7 & 36 & $62: 38$ & 58 & 56 \\
10 & 8 & 32 & $61: 39$ & 58 & 56 \\
11 & 9 & 30 & $61: 39$ & 53 & 54 \\
12 & 10 & 22 & $61: 39$ & 53 & 54 \\
13 & 11 & 16 & $63: 37$ & 52 & 54 \\
\hline
\end{tabular}

[a] Reagents and conditions: styrene (1 equiv.), ethyl diazoacetate (1 equiv.), $\mathrm{L}-\mathrm{Cu}(\mathrm{OTf})_{2}(1 \mathrm{~mol}-\%), \mathrm{CH}_{2} \mathrm{Cl}_{2}$, room temperature, yield and selectivities were determined by gas chromatography (methyl silicone and cyclodex- $\beta$ columns). (1R,2R)-trans-cyclopropane and $(1 R, 2 S)$-cis-cyclopropane are the major isomers. [b] Taken from ref. $^{[37]}$

The last ditopic ligand prepared and used in this work was InDiBox (2f). The results obtained with its corresponding copper complex are collected in Table 5.

In this case, for comparison, we also synthesized the ligand InBox modified in the bridge with one benzyl group (7) (Figure 5). The rationale for introducing just one benzyl group, was so that the structure of 7 would be closer to its homologous ditopic ligand $\mathbf{2 f}$. Consequently, the behavior of $\mathbf{7}$ should be more similar to $\mathbf{2 f}$ than in the absence of the additional benzyl moiety. Comparing those results with data obtained with $\mathrm{Cu}-\mathbf{1 f}$, it was observed that a small decrease in yield and diastereoselectivity values was evident although, contrary to this general trend, enantioselectivity increased slightly. The results obtained with $\mathrm{Cu}-\mathbf{2 f}$ are similar to those obtained with $\mathrm{Cu}-7$, and also to those previously described with analogous dibenzylated ligand $\mathbf{8}^{[37]}$ indicating again that the presence of the benzyl group in the bridge is decisive in setting complex geometry and therefore, in the mechanistic stage where selectivity is determined.

The recoverability and reapplication of the catalyst $\mathrm{Cu}-$ 2f was also found to be very good. It was possible to use this catalyst in up to 12 cycles of cyclopropanation without suffering any loss of activity or selectivity. 
Table 5. Cyclopropanation reactions between styrene and ethyl diazoacetate catalyzed by $\mathrm{Cu}-\mathrm{InBox}$ and $\mathrm{Cu}$-InDiBox. ${ }^{[a]}$

\begin{tabular}{|c|c|c|c|c|c|c|}
\hline Entry & Ligand & Run & $\begin{array}{c}\text { Yield } \\
{[\%]}\end{array}$ & trans/cis & $\begin{array}{l}\% \text { ee } \\
\text { trans }\end{array}$ & $\begin{array}{c}\% \text { ee } \\
\text { cis }\end{array}$ \\
\hline 1 & InBox (1f) & - & 86 & $62: 38$ & 78 & 76 \\
\hline 2 & InBox-Bn (7) & - & 62 & $57: 43$ & 85 & 85 \\
\hline $3^{[\mathrm{b}]}$ & InBox-2Bn (8) & - & 49 & $58: 42$ & 83 & 86 \\
\hline 4 & InDiBox (2f) & 1 & 69 & $50: 50$ & 73 & 74 \\
\hline 5 & & 2 & 50 & $50: 50$ & 83 & 79 \\
\hline 6 & & 3 & 59 & $48: 52$ & 70 & 86 \\
\hline 7 & & 4 & 59 & $45: 55$ & 77 & 82 \\
\hline 8 & & 5 & 77 & $47: 53$ & 81 & 87 \\
\hline 9 & & 6 & 79 & $46: 54$ & 64 & 82 \\
\hline 10 & & 7 & 63 & $46: 54$ & 79 & 81 \\
\hline 11 & & 8 & 70 & $46: 54$ & 73 & 80 \\
\hline 12 & & 9 & 65 & $46: 54$ & 72 & 78 \\
\hline 13 & & 10 & 71 & $46: 54$ & 70 & 78 \\
\hline 14 & & 11 & 76 & $46: 54$ & 69 & 74 \\
\hline 15 & & 12 & 49 & $46: 54$ & 65 & 74 \\
\hline
\end{tabular}

[a] Reagents and conditions: styrene (1 equiv.), ethyl diazoacetate (1 equiv.), $\mathrm{L}-\mathrm{Cu}(\mathrm{OTf})_{2}(1 \mathrm{~mol}-\%), \mathrm{CH}_{2} \mathrm{Cl}_{2}$, room temperature, yield and selectivities were determined by gas chromatography (methyl silicone and cyclodex- $\beta$ columns). (1R,2R)-trans-cyclopropane and $(1 R, 2 S)$-cis-cyclopropane are the major isomers. [b] Taken from ref. ${ }^{[37]}$

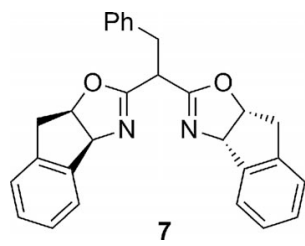

Figure 5. Structure of InBox-Bn (7).

The main objective of the preparation of coordination polymers and the use of a release-capture strategy was to develop highly recoverable catalytic systems. In our previous studies, we found that the use of ligands with more than two units of azabis(oxazoline) [TAX (3)] improved recoverability of the catalyst, probably due to more facile formation of the polymer at the end of the reaction. ${ }^{[13]}$ For this reason, we went one step beyond and designed a new family of tetratopic ligands where the azabis(oxazoline) units are connected to a tetrahedral quaternary carbon using a click chemistry-based synthetic strategy [click-QAX (4)].

According to the results presented in Table 1, the best cyclopropanation outcomes correlate to the use of ligands bearing $t \mathrm{Bu}$ and $i \mathrm{Pr}$ groups. Accordingly, we carried out the synthesis of the new click-QAX ligands containing these two different substituents. The resulting ligands were complexed with $\mathrm{Cu}(\mathrm{OTf})_{2}$ in the appropriated 2:1 Cu/Ligand stoichiometry in order to obtain the corresponding coordination polymer. The results obtained with these two ligands together with those obtained using the corresponding monotopic ligand are depicted in Table 6 and Table 7 .
Table 6. Cyclopropanation reactions of styrene and ethyl diazoacetate as catalyzed by $\mathrm{Cu}-t \mathrm{BuAzabox}$ and $\mathrm{Cu}$-click- $t$ BuQAX. ${ }^{[\mathrm{a}]}$

\begin{tabular}{|c|c|c|c|c|c|c|}
\hline Entry & Ligand & Run & $\begin{array}{c}\text { Yield } \\
{[\%]}\end{array}$ & trans/cis & $\begin{array}{l}\% \text { ee } \\
\text { trans }\end{array}$ & $\begin{array}{c}\% e e \\
\text { cis }\end{array}$ \\
\hline 1 & $t$ BuAzabox (1a) & - & 82 & $73: 27$ & 92 & 84 \\
\hline 2 & click- $t$ BuQAX & 1 & 98 & $75: 25$ & 99 & 90 \\
\hline 3 & & 2 & 96 & $74: 26$ & 99 & 90 \\
\hline 4 & & 3 & 87 & $73: 27$ & 99 & 89 \\
\hline 5 & & 4 & 95 & $72: 28$ & 98 & 89 \\
\hline 6 & & 5 & 90 & $71: 29$ & 98 & 88 \\
\hline 7 & & 6 & 84 & $71: 29$ & 97 & 88 \\
\hline 8 & & 7 & 83 & $70: 30$ & 98 & 87 \\
\hline 9 & & 8 & 76 & $69: 31$ & 98 & 87 \\
\hline 10 & & 9 & 86 & $69: 31$ & 99 & 86 \\
\hline 11 & & 10 & 79 & $69: 31$ & 98 & 85 \\
\hline 12 & & 11 & 73 & $68: 32$ & 99 & 85 \\
\hline 13 & & 12 & 84 & $67: 33$ & 99 & 85 \\
\hline 14 & & 13 & 81 & $67: 33$ & 96 & 84 \\
\hline 15 & & 14 & 85 & $67: 33$ & 96 & 85 \\
\hline 16 & & 15 & 73 & $67: 33$ & 96 & 84 \\
\hline 17 & & 16 & 90 & $67: 33$ & 97 & 85 \\
\hline 18 & & 17 & 62 & $66: 34$ & 96 & 85 \\
\hline 19 & & 18 & 81 & $66: 34$ & 95 & 84 \\
\hline 20 & & 19 & 77 & $66: 34$ & 95 & 85 \\
\hline 21 & & 20 & 50 & $66: 34$ & 91 & 84 \\
\hline
\end{tabular}

[a] Reagents and conditions: styrene (1 equiv.), ethyl diazoacetate (1 equiv.), $\mathrm{L}-\mathrm{Cu}(\mathrm{OTf})_{2}(1 \mathrm{~mol}-\%), \mathrm{CH}_{2} \mathrm{Cl}_{2}$, room temperature, yield and selectivities were determined by gas chromatography (methyl silicone and cyclodex- $\beta$ columns). (1R,2R)-trans-cyclopropane and $(1 R, 2 S)$-cis-cyclopropane are the major isomers.

Table 7. Cyclopropanation reactions between styrene and ethyl diazoacetate catalyzed by $\mathrm{Cu}-i \operatorname{PrAzabox}$ and $\mathrm{Cu}$-click-iPrQAX. ${ }^{[\mathrm{a}]}$

\begin{tabular}{|c|c|c|c|c|c|c|}
\hline Entry & Ligand & Run & $\begin{array}{l}\text { Yield } \\
{[\%]}\end{array}$ & trans/cis & $\begin{array}{l}\% \text { ee } \\
\text { trans }\end{array}$ & $\begin{array}{c}\% \text { ee } \\
\text { cis }\end{array}$ \\
\hline 1 & $i$ PrAzabox (1b) & - & 45 & $71: 29$ & 74 & 57 \\
\hline 2 & click- $i \operatorname{PrQAX}$ (4b) & 1 & 75 & $67: 33$ & 26 & 21 \\
\hline 3 & & 2 & 74 & $68: 32$ & 53 & 39 \\
\hline 4 & & 3 & 69 & $69: 31$ & 82 & 53 \\
\hline 5 & & 4 & 86 & $68: 32$ & 75 & 56 \\
\hline 6 & & 5 & 82 & $69: 31$ & 76 & 60 \\
\hline 7 & & 6 & 71 & $63: 37$ & 78 & 60 \\
\hline 8 & & 7 & 81 & $63: 37$ & 80 & 63 \\
\hline 9 & & 8 & 63 & $68: 32$ & 86 & 64 \\
\hline 10 & & 9 & 64 & $67: 33$ & 83 & 66 \\
\hline 11 & & 10 & 77 & $66: 34$ & 84 & 65 \\
\hline 12 & & 11 & 67 & $66: 34$ & 80 & 68 \\
\hline 13 & & 12 & 62 & $66: 34$ & 85 & 69 \\
\hline 14 & & 13 & 48 & $66: 34$ & 86 & 69 \\
\hline
\end{tabular}

[a] Reagents and conditions: styrene ( 1 equiv.), ethyl diazoacetate (1 equiv.), $\mathrm{L}-\mathrm{Cu}(\mathrm{OTf})_{2}(1 \mathrm{~mol}-\%), \mathrm{CH}_{2} \mathrm{Cl}_{2}$, room temperature, yield and selectivities were determined by gas chromatography (methyl silicone and cyclodex- $\beta$ columns). (1R,2R)-trans-cyclopropane and $(1 R, 2 S)$-cis-cyclopropane are the major isomers.

As shown in Table 6, results obtained with complex $\mathrm{Cu}$ $4 \mathbf{a}$ are remarkable; both the yield and the enantioselectivity are close to $100 \%$ (Table 6, Entry 2), a substantial improvement over data found using complex Cu-1a (Table 6, Entry 1). In addition, the quality of data obtained using $\mathrm{Cu}-\mathbf{4 a}$ was, to a large extent, retained over the course of the 19 subsequent runs with recovered catalyst. Only in the last run was any substantial decrease in yield observed $(50 \%)$ (Table 6, Entry 21). Run 21 data notwithstanding it is im- 
portant to point out that these results are the best yet obtained for this reaction and this type of catalyst complex.

Finally, complex $\mathrm{Cu}-\mathbf{4 b}$ was applied to the cyclopropanation reaction (Table 7). As shown in the Table, although product yields during all the cycles are better than those obtained using monotopic ligand complex $\mathrm{Cu}-\mathbf{1 b}$, the enantioselectivity found in the first two cycles was exceedingly low. Interestingly, after the second cycle of reaction, enantioselectivity induced by $\mathrm{Cu}-\mathbf{4 b}$ increased, even exceeding the enantioselectivity induced during cyclopropanations with $\mathrm{Cu}-\mathbf{1 b}$. We attribute this change in $\mathrm{Cu}-\mathbf{4 b}$-induced enantioselectivity to the presence of free copper in the reaction medium introduced during initial complexation. Free $\mathrm{Cu}(\mathrm{OTf})_{2}$ catalyzes the racemic reaction and this would explain the poor ee values noted for runs 1 and 2 with $\mathrm{Cu}-4 \mathbf{b}$ (Table 7, Entries 2 and 3). We envision that, after two reaction cycles, all unbound copper would have been extracted. Consequently, enantioselectivity values associated with $\mathrm{Cu}-\mathbf{4 b}$ (generated during runs 3-20) would now be comparable to those noted for complex $\mathrm{Cu}-\mathbf{1 b}$.

As with the other coordination polymers, the recoverability of $\mathrm{Cu}-\mathbf{4 b}$ was found to be excellent. In this case, up to 13 runs could be carried out affording both good yields and enantioselectivities.

\section{Conclusions}

In this work we have described the preparation of several new polytopic chiral ligands based on bis(oxazoline) units, both ditopic ( $t$ BuDiBox, PhDiBox, and InDiBox) and tetratopic (click- $t$ BuQAX and click-iPrQAX). The copper complexes of these ligands have been tested in a benchmark asymmetric cyclopropanation reaction, using a release-capture strategy based on the formation of coordination polymers at the end of the reaction to recover and recycle catalysts. The use of this strategy has allowed, in the case of the tetratopic ligands, the recovery and reuse of catalysts in at least up to 20 reaction cycles leading to very good yields and enantioselectivities. These results are among the best described thus far for a recoverable catalyst in this kind of reaction. These findings broaden the scope of application for this recycling strategy and also highlight its strength as a convergence of the best of the homogeneous and heterogeneous catalysis worlds.

\section{Experimental Section}

General Information: All reactions were carried out under an argon atmosphere in oven-dried glassware. Anhydrous solvents such as tetrahydrofuran, dichloromethane, and hexane were obtained from an SPS-device. The purchased reagents were used as received without further purification. Amino acids were used as commercially available. The starting azabis(oxazolines) and 1,3-diazido-2,2-bis(azidomethyl)propane were prepared according to literature procedures. ${ }^{[17-20,38]}$ The chemical shifts were relative to TMS as an internal reference for ${ }^{1} \mathrm{H}$ NMR spectroscopy.

Synthesis of 1,4-Bis\{2,2-bis[(4S)-4-phenyl-4,5-dihydrooxazol-2yl]ethyl benzene (PhDiBox) (2e) as a representative procedure: $\mathrm{A}$ solution of 2,2'-methylene-bis[(4S)-4-phenyl-4,5-dihydrooxazole] (306 $\mathrm{mg}, 1 \mathrm{mmol})$ in anhydrous tetrahydrofuran $(5 \mathrm{~mL})$ was combined with another solution of $t \mathrm{BuOK}(112 \mathrm{mg}, 1 \mathrm{mmol})$ also in anhydrous tetrahydrofuran $(5 \mathrm{~mL})$. After stirring for $1 \mathrm{~h}$ at room temperature, $\alpha, \alpha^{\prime}$-Dibromo- $p$-xylene $(132 \mathrm{mg}, 0.5 \mathrm{mmol})$ was added. The mixture was stirred at $77^{\circ} \mathrm{C}$ overnight. The solvent was evaporated under reduced pressure and the residue was partitioned between ethyl acetate $(10 \mathrm{~mL})$ and a saturated $\mathrm{NaCl}$ solution $(10 \mathrm{~mL})$. The aqueous phase was extracted with ethyl acetate $(3 \mathrm{X}$ $10 \mathrm{~mL}$ ) and the combined organic phases were dried with anhydrous $\mathrm{MgSO}_{4}$. Evaporation of the solvent yielded the product as a light yellow solid.

1,4-Bis $\{2,2$-bis $[(\mathrm{S})-4$-tertbutyl-4,5-dihydrooxazol-2-yl]ethyl $\}$ benzene $(\boldsymbol{t B u D i B o x})$ (2c): Yellow solid in almost quantitative yield. $[\alpha]_{\mathrm{D}}^{20}=$ $-72.3\left(c=2.3, \mathrm{CH}_{2} \mathrm{Cl}_{2}\right)$; m.p. $75-77{ }^{\circ} \mathrm{C} .{ }^{1} \mathrm{H}$ NMR $(400 \mathrm{MHz}$, $\left.\mathrm{CDCl}_{3}\right): \delta=7.12(\mathrm{~s}, 4 \mathrm{H}), 4.06(\mathrm{~m}, 8 \mathrm{H}), 3.78(\mathrm{~m}, 4 \mathrm{H}), 3.37(\mathrm{~m}, 2$ H), $3.14(\mathrm{~m}, 4 \mathrm{H}), 0.89(\mathrm{~s}, 9 \mathrm{H}), 0.83(\mathrm{~s}, 9 \mathrm{H}), 0.82(\mathrm{~s}, 9 \mathrm{H}), 0.77$ $(\mathrm{s}, 9 \mathrm{H}) \mathrm{ppm} .{ }^{13} \mathrm{C} \mathrm{NMR}\left(100 \mathrm{MHz}, \mathrm{CDCl}_{3}\right): \delta=164.11,164.06$, $163.8,163.7,136.39,136.3,130.4,130.0,129.0,128.5,75.6,75.5$, $68.85,68.80,41.3,41.2,35.4,33.9,33.75,33.70,33.54,25.85,25.83$, $25.69,25.68,25.66,25.64 \mathrm{ppm}$. IR $(\mathrm{C}=\mathrm{N}): \tilde{v}=1654 \mathrm{~cm}^{-1}$. HRMS $\left(\mathrm{ESI}^{+}\right): m / z=635.4531[\mathrm{M}+\mathrm{H}]^{+}$, calcd. for $\mathrm{C}_{38} \mathrm{H}_{58} \mathrm{~N}_{4} \mathrm{O}_{4} \mathrm{H}$ : 635.4536 .

1,4-Bis $\{2,2-b i s[(S)-4-i s o p r o p y l-4,5-d i h y d r o o x a z o l-2-y l]$ ethyl $\}$ benzene (iPrDiBox) (2d): Transparent oil in almost quantitative yield: $[\alpha]_{\mathrm{D}}^{25}$ $=-57.5\left(\mathrm{c} 0.54, \mathrm{CHCl}_{3}\right) ;{ }^{1} \mathrm{H} \mathrm{NMR}\left(400 \mathrm{MHz}, \mathrm{CDCl}_{3}\right): \delta=7.10(\mathrm{~s}$, $4 \mathrm{H}), 4.28-4.06(\mathrm{~m}, 4 \mathrm{H}), 4.01-3.79(\mathrm{~m}, 8 \mathrm{H}), 3.76-3.63(\mathrm{~m}, 2 \mathrm{H})$, 3.25-3.05 (m, $4 \mathrm{H}), 1.79-155(\mathrm{~m}, 4 \mathrm{H}), 0.89(\mathrm{~d}, J=6.8 \mathrm{~Hz}, 6 \mathrm{H})$, $0.82(\mathrm{~d}, J=6.8 \mathrm{~Hz}, 6 \mathrm{H}), 0.81(\mathrm{~d}, J=6.8 \mathrm{~Hz}, 6 \mathrm{H}), 0.75(\mathrm{~d}, J=$ $6.8 \mathrm{~Hz}, 6 \mathrm{H}) \mathrm{ppm} .{ }^{13} \mathrm{C} \mathrm{NMR}\left(100 \mathrm{MHz}, \mathrm{CDCl}_{3}\right): \delta=164.0,163.9$, $136.4,128.9,71.82,71.81,70.05,70.04,41.3,35.4,32.3,32.2,18.6$, 18.5, 17.8, 17.7 ppm. IR $(\mathrm{C}=\mathrm{N}): \tilde{v}=1665.2 \mathrm{~cm}^{-1}$. HRMS $\left(\mathrm{ESI}^{+}\right)$ $m / z=579.3931[\mathrm{M}+\mathrm{H}]^{+}$, calcd. for $\mathrm{C}_{34} \mathrm{H}_{50} \mathrm{~N}_{4} \mathrm{O}_{4}+\mathrm{H} 579.3910$.

1,4-Bis $\{2,2$-bis [(4S)-4-phenyl-4,5-dihydrooxazol-2-yl]ethyl $\}$ benzene (PhDiBox) (2e): Light yellow solid in almost quantitative yield. $[\alpha]_{\mathrm{D}}^{25}=-42.0\left(\mathrm{c} 0.6, \mathrm{CH}_{3} \mathrm{OH}\right)$; m.p. $86-89{ }^{\circ} \mathrm{C} .{ }^{1} \mathrm{H}$ NMR $(400 \mathrm{MHz}$, $\left.\mathrm{CDCl}_{3}\right): \delta=7.36-4.14(\mathrm{~m}, 20 \mathrm{H}), 7.09-6.99(\mathrm{~m}, 4 \mathrm{H}), 5.26-5.11$ $(\mathrm{m}, 4 \mathrm{H}), 4.69-4.55(\mathrm{~m}, 4 \mathrm{H}), 4.20-4.12(\mathrm{~m}, 2 \mathrm{H}), 4.11-3.95(\mathrm{~m}, 4$ $\mathrm{H}), 3.48-3.35(\mathrm{~m}, 4 \mathrm{H}) \mathrm{ppm} .{ }^{13} \mathrm{C} \mathrm{NMR}\left(100 \mathrm{MHz}, \mathrm{CDCl}_{3}\right): \delta=$ $165.49,165.37,141.96,141.90,136.39,130.72,129.27,128.65$, $128.59,127.56,127.53,126.78,126.75,126.66,126.61,125.47$, $125.44,75.34,75.15,69.53,69.54,41.4,35.4 \mathrm{ppm}$. IR $(\mathrm{C}=\mathrm{N}): \tilde{v}$ $=1657 \mathrm{~cm}^{-1}$. HRMS $\left(\mathrm{ESI}^{+}\right) \mathrm{m} / z=715.3288[\mathrm{M}+\mathrm{H}]^{+}$, calcd. for $\mathrm{C}_{46} \mathrm{H}_{43} \mathrm{~N}_{4} \mathrm{O}_{4}+\mathrm{H} 715.3284$.

1,4-Bis $\{2,2-b i s[(3 a R, 8 a S)-8,8 a-d i h y d r o-3 a H-i n d e n o[1,2-d]$ oxazol-2yl]ethyl benzene (InDiBox) (2f): Yellow solid in almost quantitative yield. $[\alpha]_{\mathrm{D}}^{25}=-209.5$ (c $0.58, \mathrm{CH}_{3} \mathrm{OH}$ ); m.p. $88-91{ }^{\circ} \mathrm{C} ;{ }^{1} \mathrm{H}$ NMR $\left(400 \mathrm{MHz}, \mathrm{CDCl}_{3}\right): \delta=7.50-7.45(\mathrm{~m}, 2 \mathrm{H}), 7.40-7.15(\mathrm{~m}, 18 \mathrm{H})$, $5.51(\mathrm{~d}, J=7.8 \mathrm{~Hz}, 2 \mathrm{H}), 5.47(\mathrm{~d}, J=7.6 \mathrm{~Hz}, 2 \mathrm{H}), 5.29-5.21(\mathrm{~m}$, $4 \mathrm{H}), 3.46(\mathrm{t}, J=8.4 \mathrm{~Hz}, 2 \mathrm{H}), 3.35-3.25(\mathrm{~m}, 4 \mathrm{H}), 3.05-2.87(\mathrm{~m}$, $8 \mathrm{H}) \mathrm{ppm} .{ }^{13} \mathrm{C} \mathrm{NMR}\left(100 \mathrm{MHz}, \mathrm{CDCl}_{3}\right): \delta=167.2,164.8,164.5$, $164.4,141.6,139.8,139.7,139.5,135.3,135.2,134.0,129.9,128.4$, $128.3,128.0,127.5,127.3,125.6,125.5,125.2,125.0,83.4,83.1$, 76.4, 76.3, 76.2, 41.2, 41.1, 39.6, 39.5, 39.2, 38.3, 35.1, 29.7 ppm. IR $(\mathrm{C}=\mathrm{N}): \tilde{v}=1652 \mathrm{~cm}^{-1}$. HRMS $\left(\mathrm{ESI}^{+}\right) \mathrm{m} / z=763.3296[\mathrm{M}+$ $\mathrm{H}^{+}$, calcd. for $\mathrm{C}_{50} \mathrm{H}_{43} \mathrm{~N}_{4} \mathrm{O}_{4}+\mathrm{H} 763.3285$.

Synthesis of 2,2'-(2-Phenyletano-1,1-diyl)bis(8,8a-dihydro-3aHindano $[1,2-d]$ oxazol) (InBox-Bn) (7): A solution of bis $[(3 \mathrm{a} R, 8 \mathrm{a} S)$ 8,8a-dihydro-3a $H$-indeno[1,2- $d$ ] oxazol-2-yl]methane $\quad$ (200 mg, $0.61 \mathrm{mmol})$ in anhydrous tetrahydrofuran $(5 \mathrm{~mL})$ was combined with another solution of $t \mathrm{BuOK}(67.8 \mathrm{mg}, 0.61 \mathrm{mmol})$ also in anhydrous tetrahydrofuran $(5 \mathrm{~mL})$. After stirring for $1 \mathrm{~h}$ at room tem- 
perature, benzyl bromide $(103.6 \mathrm{mg}, 0.61 \mathrm{mmol})$ was added. The mixture was stirred at $77^{\circ} \mathrm{C}$ overnight. The solvent was evaporated under reduced pressure and the residue was partitioned between ethyl acetate $(10 \mathrm{~mL})$ and a saturated $\mathrm{NaCl}$ solution $(10 \mathrm{~mL})$. The aqueous phase was extracted with ethyl acetate $(3 \mathrm{X} 10 \mathrm{~mL})$ and the combined organic phases were dried with anhydrous $\mathrm{MgSO}_{4}$. The product was purified by medium pressure liquid chromatography. A light yellow solid is obtained with $68 \%$ of isolated yield. $[\alpha]_{\mathrm{D}}^{20}=-252.0\left(c=0.7, \mathrm{CH}_{3} \mathrm{OH}\right) ;$ m.p. $161-163{ }^{\circ} \mathrm{C} ;{ }^{1} \mathrm{H}$ NMR $\left(400 \mathrm{MHz}, \mathrm{CDCl}_{3}\right): \delta=7.52-7.50(\mathrm{~m}, 1 \mathrm{H}), 7.35-7.20(\mathrm{~m}, 7 \mathrm{H})$, 6.99-6.85 (m, $5 \mathrm{H}), 5.54(\mathrm{~d}, J=8 \mathrm{~Hz}, 1 \mathrm{H}), 5.50(\mathrm{~d}, J=7.6 \mathrm{~Hz}, 1$ H), 5.32-5.24 (m, $2 \mathrm{H}), 3.59$ (t, $J=8.4 \mathrm{~Hz}, 1 \mathrm{H}), 3.33$ (dd, $J=9.6$, $J=18 \mathrm{~Hz}, 1 \mathrm{H}), 3.31(\mathrm{dd}, J=10, J=18 \mathrm{~Hz}, 1 \mathrm{H}), 3.18-2.93(\mathrm{~m}$, $4 \mathrm{H}) \mathrm{ppm} .{ }^{13} \mathrm{C}$ NMR $\left(100 \mathrm{MHz}, \mathrm{CDCl}_{3}\right): \delta=164.7,164.3,141.6$, $141.6 ; 139.7,139.5,137.4,128.7,128.4,128,3 ; 128,0 ; 127,3 ; 126,3$; 125,$6 ; 125,5 ; 125,2 ; 125,1 ; 83,5 ; 83,2 ; 76,6 ; 76.3,41.3,39.6,39.5$, $35.6 \mathrm{ppm}$. IR $(\mathrm{C}=\mathrm{N}): \tilde{v}=1647.61 \mathrm{~cm}^{-1}$. HRMS $(\mu-\mathrm{TOF}) \mathrm{m} / \mathrm{z}=$ $421.1911[\mathrm{M}+\mathrm{H}]^{+}$, calcd. for $\mathrm{C}_{28} \mathrm{H}_{24} \mathrm{~N}_{2} \mathrm{O}_{2} \mathrm{H}=421.1916$.

Synthesis of (click- $t$ BuQAX) (4a) as a Representative Procedure: $(S)$ 4-tert-Butyl- $N$ - $[(S)$-4-tert-butyl-4,5-dihydrooxazol-2-yl]- $N$-(prop-2ynyl)-4,5-dihydrooxazol-2-amine (4) (1.00 mmol, $291.4 \mathrm{mg}), 1,3$-diazido-2,2-bis(azidomethyl)propane $(0.25 \mathrm{mmol}, 59 \mathrm{mg})$ and $\mathrm{CuI}$ $(0.05 \mathrm{mmol}, 9.5 \mathrm{mg})$ were dissolved in $9 \mathrm{~mL}$ of $\mathrm{CH}_{2} \mathrm{Cl}_{2}$ and $2 \mathrm{~mL}$ of $\mathrm{Et}_{3} \mathrm{~N}$. The mixture was stirred during $20 \mathrm{~h}$ at room temperature. After this time, the solvent was evaporated under reduced pressure and the residue partitioned between $10 \mathrm{~mL}$ of $\mathrm{CH}_{2} \mathrm{Cl}_{2}$ and a $1 \%$ EDTA-2Na (ethylenediaminotetraacetic acid disodium salt) aqueous solution. The aqueous phases were extracted with $\mathrm{CH}_{2} \mathrm{Cl}_{2}$ and the combined organic phases dried with anhydrous $\mathrm{Na}_{2} \mathrm{SO}_{4}$ and subsequently, evaporated under vacuum. A recrystallization in acetone yielded dark brown crystals of the product in almost quantitative yield.

click-tBuQAX (4a): Brown solid. $[\alpha]_{\mathrm{D}}^{20}=-59\left(0.7, \mathrm{CH}_{2} \mathrm{Cl}_{2}\right)$; m.p. 73-75 ${ }^{\circ} \mathrm{C}$; ${ }^{1} \mathrm{H}$ NMR $\left(400 \mathrm{MHz}, \mathrm{CDCl}_{3}\right): \delta=8.10-8.07(\mathrm{~m}, 4 \mathrm{H})$, $5.23-5.10(\mathrm{~m}, 8 \mathrm{H}), 4.36-4.29(\mathrm{~m}, 16 \mathrm{H}), 4.25-4.19(\mathrm{~m}, 8 \mathrm{H}), 3.82-$ $3.76(\mathrm{~m}, 8 \mathrm{H}), 0.85-0.80(\mathrm{~m}, 72 \mathrm{H}) \mathrm{ppm} .{ }^{13} \mathrm{C}$ NMR $(100 \mathrm{MHz}$, $\left.\mathrm{CDCl}_{3}\right): \delta=156.9,144.2,130.2,73.2,70.3,51.4,45.2,33.9,29.7$, $25.5 \mathrm{ppm}$. IR $(\mathrm{C}=\mathrm{N}): \tilde{v}=1636 \mathrm{~cm}^{-1}$. HRMS $\left(\mathrm{ESI}^{+}\right) \mathrm{m} / \mathrm{z}=$ $1458.9554[\mathrm{M}+2 \mathrm{H}]^{+}$, calcd. for $\mathrm{C}_{65} \mathrm{H}_{100} \mathrm{~N}_{24} \mathrm{O}_{8} \mathrm{H}_{2}$ : 1458.9564 .

click-iPrQAX (4b): Brown solid. $[\alpha]_{\mathrm{D}}^{20}=-48.0\left(c=1.9, \mathrm{CH}_{2} \mathrm{Cl}_{2}\right)$; m.p.68-71 ${ }^{\circ} \mathrm{C} .{ }^{1} \mathrm{H}$ NMR $\left(400 \mathrm{MHz}, \mathrm{CDCl}_{3}\right): \delta=8.16-8.08$ (m, 4 H), 5.19-5.11 (m, $8 \mathrm{H}), 4.44-4.34(\mathrm{~m}, 8 \mathrm{H}), 4.32-4.23(\mathrm{~m}, 8 \mathrm{H})$, $4.16-4.06(\mathrm{~m}, 8 \mathrm{H}), 3.90-3.78(\mathrm{~m}, 8 \mathrm{H}), 1.77-1.61(\mathrm{~m}, 8 \mathrm{H}), 0.87$ $(\mathrm{d}, J=6.7 \mathrm{~Hz}, 24 \mathrm{H}), 0.78(\mathrm{~d}, J=6.7 \mathrm{~Hz}, 24 \mathrm{H}) \mathrm{ppm} .{ }^{13} \mathrm{C} \mathrm{NMR}$ $\left(100 \mathrm{MHz}, \mathrm{CDCl}_{3}\right): \delta=156.7,144.0,127.9,71.6,69.8,49.1,44.9$, $32.7,29.6,18.7,17.7 \mathrm{ppm}$. IR $(\mathrm{C}=\mathrm{N}): \tilde{v}=1637 \mathrm{~cm}^{-1}$. HRMS $\left(\mathrm{ESI}^{+}\right) m / z=1345.8229[\mathrm{M}+\mathrm{H}]^{+}$, calcd. for $\mathrm{C}_{65} \mathrm{H}_{100} \mathrm{~N}_{24} \mathrm{O}_{8} \mathrm{H}: 1345$. 8234.

General Procedure for the Preparation of the Copper(II)-Ligand Coordination Polymers: The ligand-copper coordination polymers were prepared by dissolving $0.02 \mathrm{mmol}$ of $\mathrm{Cu}(\mathrm{OTf})_{2}$ and $0.02 \mathrm{mmol}$ of the corresponding ditopic ligand in $1 \mathrm{~mL}$ of anhydrous dichloromethane. The resulting clear solution was stirred for $15 \mathrm{~min}$. After this time the corresponding coordination polymer formed appeared as a green solid precipitate, and could be used in the catalytic tests without further treatment.

General Procedure for the Cyclopropanation Reactions: Ethyl diazoacetate $(2.00 \mathrm{mmol})$ was slowly added by syringe pump to a solution of the corresponding alkene $(2.00 \mathrm{mmol}), n$-decane $(100 \mathrm{mg}$; internal standard) and the polymeric catalyst $(0.02 \mathrm{mmol})$ in $2 \mathrm{~mL}$ of anhydrous dichloromethane at room temperature. During the addition of ethyl diazoacetate the solid polymer disappeared and a clear solution appeared instead. After total consumption of the diazoacetate (approx. $24 \mathrm{~h}$ ) the polymer catalyst precipitated again. The solution was concentrated to $0.5 \mathrm{~mL}$ and the solid washed with $\mathrm{n}$-hexane and dried. In these conditions the catalyst was ready to be used again in a new reaction. Reactions were monitored by gas chromatography using an FID detector connected to a HewlettPackard 5890 II chromatograph, using a cross-linked methyl silicone column: $25 \mathrm{mX} 0.25 \mathrm{~mm} \mathrm{X} 0.25 \mu \mathrm{m}$; helium was used as carrier gas. Column pressure: $20 \mathrm{psi}$; injector temperature: $230^{\circ} \mathrm{C}$; detector temperature: $250{ }^{\circ} \mathrm{C}$; oven program: $70{ }^{\circ} \mathrm{C}(3 \mathrm{~min}), 15^{\circ} \mathrm{C}$ $\mathrm{min}^{-1}$ to $200{ }^{\circ} \mathrm{C}(5 \mathrm{~min})$. The enantioselectivities of the reactions were also determined in all cases by gas chromatography using a Cyclodex $-\beta$ column. Temperature program: $120^{\circ} \mathrm{C}$ isotherm. Specific chromatographic conditions, retention times and some typical chromatograms are gathered in the Supporting Information.

Supporting Information (see footnote on the first page of this article): ${ }^{1} \mathrm{H}$ and ${ }^{13} \mathrm{C}$ NMR spectra of the new ligands. Typical gas chromatograms of the cyclopropanation reaction between styrene and ethyl diazoacetate.

\section{Acknowledgments}

Financial support from the Spanish Ministerio de Economía y Competitividad (MINECO) (project number CTQ2011-28124C02-01), the European Social Fund (ESF) and the Gobierno de Aragón (Grupo Consolidado E11) is gratefully acknowledged. The authors also thank Ana C. Gallego, from the Service of Electron Microscopy of Materials of the University of Zaragoza for her valuable assistance in the FESEM experiments. One of the authors $(\mathrm{ACM})$ is indebted to the Consejo Superior de Investigaciones Científicas for a grant (CSIC JAE-Pre program).

[1] D. E. D. Vos, I. F. J. Vankelecom, P. A. Jacobs (Eds.) Chiral Catalyst Immobilization and Recycling, Wiley- $\mathrm{VCH}$, Weinheim, Germany, 2007.

[2] J. Dupont, R. F. de Souza, P. A. Z. Suarez, Chem. Rev. 2002, 102, 3667-3692.

[3] Q.-H. Fan, Y.-M. Li, A. S. C. Chan, Chem. Rev. 2002, 102, $3385-3466$.

[4] C. E. Song, S. Lee, Chem. Rev. 2002, 102, 3495-3524.

[5] D. E. Bergbreiter, J. Tian, C. Hongfa, Chem. Rev. 2009, 109, $530-582$.

[6] J. M. Fraile, J. I. García, J. A. Mayoral, Chem. Rev. 2009, 109, 360-417.

[7] J. M. Fraile, J. I. García, C. I. Herrerías, J. A. Mayoral, E. Pires, Chem. Soc. Rev. 2009, 38, 695-706.

[8] B. W. T. Gruijters, M. A. C. Broeren, F. L. van Delft, R. P. Sijbesma, P. H. H. Hermkens, F. P. J. T. Rutjes, Org. Lett. 2006, 8, 3163-3166.

[9] D.-W. Kim, S.-G. Lim, C.-H. Jun, Org. Lett. 2006, 8, 29372940.

[10] L. Shi, X. Wang, C. A. Sandoval, M. Li, Q. Qi, Z. Li, K. Ding, Angew. Chem. 2006, 118, 4214; Angew. Chem. Int. Ed. 2006, $45,4108-4112$.

[11] S.-W. Chen, J. H. Kim, C. E. Song, S. Lee, Org. Lett. 2007, 9, $3845-3848$.

[12] J. I. García, B. López-Sánchez, J. A. Mayoral, Org. Lett. 2008, 10, 4995-4998.

[13] J. I. García, C. I. Herrerías, B. López-Sánchez, J. A. Mayoral, O. Reiser, Adv. Synth. Catal. 2011, 353, 2691-2700.

[14] B. Angulo, J. I. García, C. I. Herrerías, J. A. Mayoral, A. C. Miñana, J. Org. Chem. 2012, 77, 5525-5532.

[15] L. Aldea, I. Delso, M. Hager, M. Glos, J. I. García, J. A. Mayoral, O. Reiser, Tetrahedron 2012, 68, 3417-3422.

[16] L. Aldea, J. I. García, J. A. Mayoral, Dalton Trans. 2012, 41, $8285-8289$. 
[17] A. Gissibl, M. G. Finn, O. Reiser, Org. Lett. 2005, 7, 23252328.

[18] A. Gissibl, C. Padié, M. Hager, F. Jaroschik, R. Rasappan, E. Cuevas-Yañez, C.-O. Turrin, A.-M. Caminade, J.-P. Majoral, O. Reiser, Org. Lett. 2007, 9, 2895-2898.

[19] H. Werner, R. Vicha, A. Gissibl, O. Reiser, J. Org. Chem. 2003, 68, 10166-10168.

[20] A. Schaetz, M. Hager, O. Reiser, Adv. Funct. Mater. 2009, 19, 2109-2115.

[21] C. W. Tornøe, M. Meldal, in: Peptides: The Wave of the Future (Eds.: M. Lebl, R. A. Houghten), American Peptide Society and Kluwer Academic Publishers, San Diego, 2001, p. 263264.

[22] V. V. Rostovtsev, L. G. Green, V. V. Fokin, K. B. Sharpless, Angew. Chem. 2002, 114, 2708; Angew. Chem. Int. Ed. 2002, 41, 2596-2599.

[23] C. W. Tornøe, C. Christensen, M. Meldal, J. Org. Chem. 2002, 67, 3057-3064.

[24] D. A. Evans, K. A. Woerpel, M. M. Hinman, M. M. Faul, J. Am. Chem. Soc. 1991, 113, 726-728.

[25] J. M. Fraile, J. I. García, M. J. Gil, V. Martínez-Merino, J. A. Mayoral, L. Salvatella, Chem. Eur. J. 2004, 10, 758-765.

[26] K. F. Morris, C. S. Johnson, J. Am. Chem. Soc. 1992, 114, 3139-3141.

[27] K. F. Morris, C. S. Johnson, J. Am. Chem. Soc. 1993, 115, $4291-4299$.
[28] I. Keresztes, P. G. Williard, J. Am. Chem. Soc. 2000, 122, $10228-10229$.

[29] X. Xie, C. Auel, W. Henze, R. M. Gschwind, J. Am. Chem. Soc. 2003, 125, 1595-1601.

[30] M. Isola, F. Balzano, V. Liuzzo, F. Marchetti, A. Raffaelli, G. Uccello Barretta, Eur. J. Inorg. Chem. 2008, 1363-1375.

[31] L. Allouche, A. Marquis, J.-M. Lehn, Chem. Eur. J. 2006, 12, $7520-7525$.

[32] H. Fritschi, U. Leutenegger, A. Pfaltz, Helv. Chim. Acta 1988, $71,1553-1565$

[33] B. F. Straub, P. Hofmann, Angew. Chem. 2001, 113, 1328; Angew. Chem. Int. Ed. 2001, 40, 1288-1290.

[34] J. M. Fraile, J. I. García, V. Martínez-Merino, J. A. Mayoral, L. Salvatella, J. Am. Chem. Soc. 2001, 123, 7616-7625.

[35] X. Dai, T. H. Warren, J. Am. Chem. Soc. 2004, 126, 1008510094.

[36] P. Hofmann, I. V. Shishkov, F. Rominger, Inorg. Chem. 2008, 47, 11755-11762.

[37] M. I. Burguete, J. M. Fraile, J. I. García, E. García-Verdugo, C. I. Herrerías, S. V. Luis, J. A. Mayoral, J. Org. Chem. 2001, 66, 8893-8901.

[38] W. Hayes, H. M. Osborn, S. D. Osborne, R. A. Rastall, B. Romagnoli, Tetrahedron 2003, 59, 7983-7996. 
Title: Polytopic bis(oxazoline) based ligands for the development of recoverable catalytic systems applied to the cyclopropanation reaction

Author(s): José I. García, ${ }^{*}$ Clara I. Herrerías, ${ }^{*}$ José A. Mayoral, Ana C. Miñana, and Carlos Sáenz

\section{Content}

1. NMR spectra of 1,4-bis(2,2-bis((S)-4-tert-butyl-4,5-dihydrooxazol-2-yl)ethyl)benzene $(t$ BuDiBox) (2c)

2. NMR spectra of 1,4-bis(2,2-bis((4S)-4-phenyl-4,5-dihydrooxazol-2-yl)ethyl)benzene (PhDiBox) (2d)

3. NMR spectra of 1,4-bis(2,2-bis((3a $R, 8 \mathrm{a} S)$-8,8a-dihydro-3a $H$-indeno[1,2-d]oxazol-2-yl)ethyl) benzene (InDiBox) (2f)

4. NMR spectra of 2,2'-(2-phenyletano-1,1-diyl)bis(8,8a-dihydro-3a $H$-indano[1,2-d]oxazol)

(InBox-Bn) (7)

5. NMR spectra of click-tBuQAX (4a)

6. NMR spectra of click-iPrQAX (4b)

7. Gas chromatography analyses of the Cyclopropanation reaction of styrene with ethyl diazoacetate 

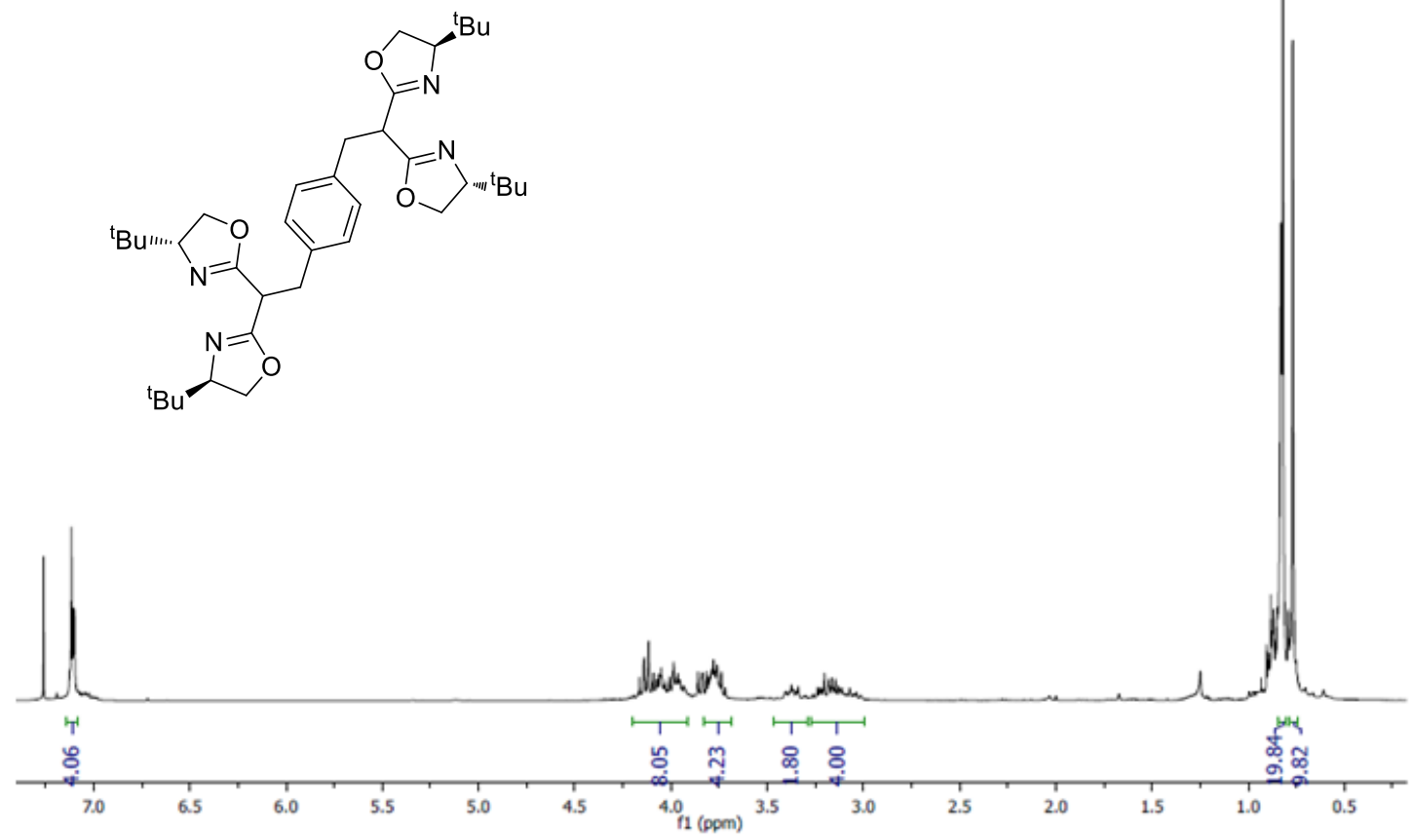

$\left(\mathrm{CDCl}_{3}, \delta \mathrm{ppm}, 400 \mathrm{MHz}\right): 7.12(\mathrm{~s}, 4 \mathrm{H}), 4.06(\mathrm{~m}, 8 \mathrm{H}), 3.78(\mathrm{~m}, 4 \mathrm{H}), 3.37(\mathrm{~m}, 2 \mathrm{H}), 3.14(\mathrm{~m}, 4 \mathrm{H}), 0.89(\mathrm{~s}, 9 \mathrm{H}), 0.83(\mathrm{~s}, 9 \mathrm{H})$, $0.82(\mathrm{~s}, 9 \mathrm{H}), 0.77(\mathrm{~s}, 9 \mathrm{H})$.

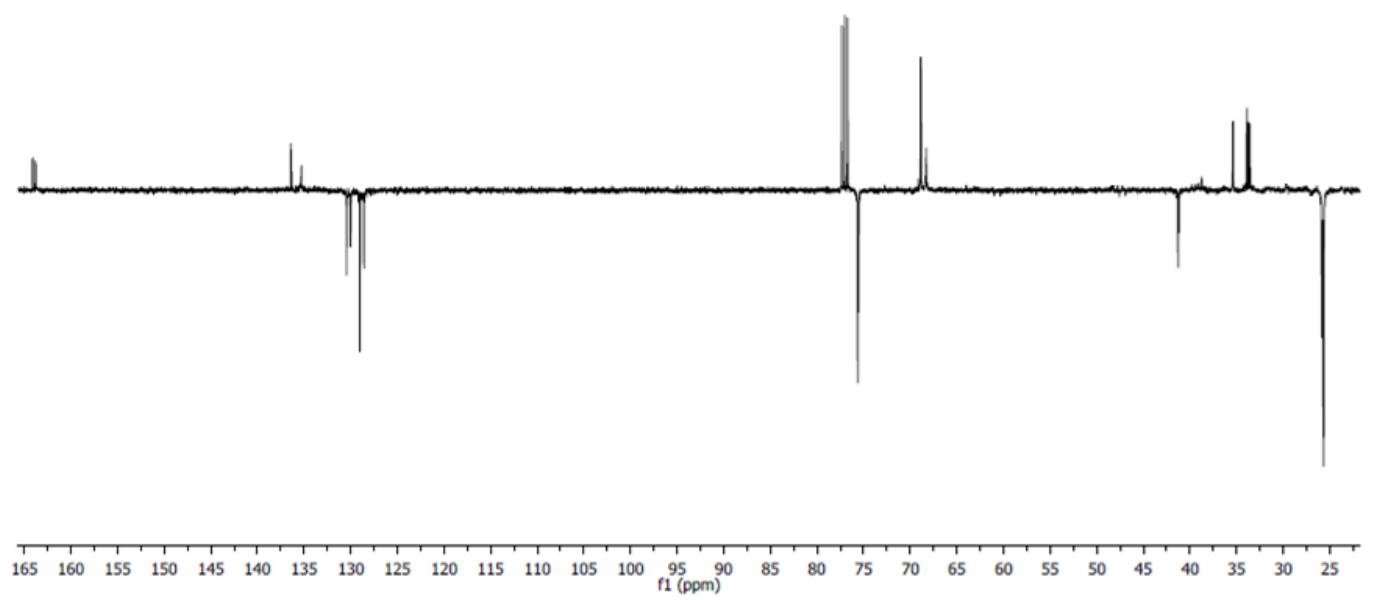

$\left(\mathrm{CDCl}_{3}, \delta \mathrm{ppm}, 100 \mathrm{MHz}\right): 164.0,163.8,136.4,130.4,130.0,129.0,128.5,75.6,75.6,68.2,68.2,41.3,41.1,36.3,33.9,33.7$, $33.5,29.6,25.8,25.7$ 


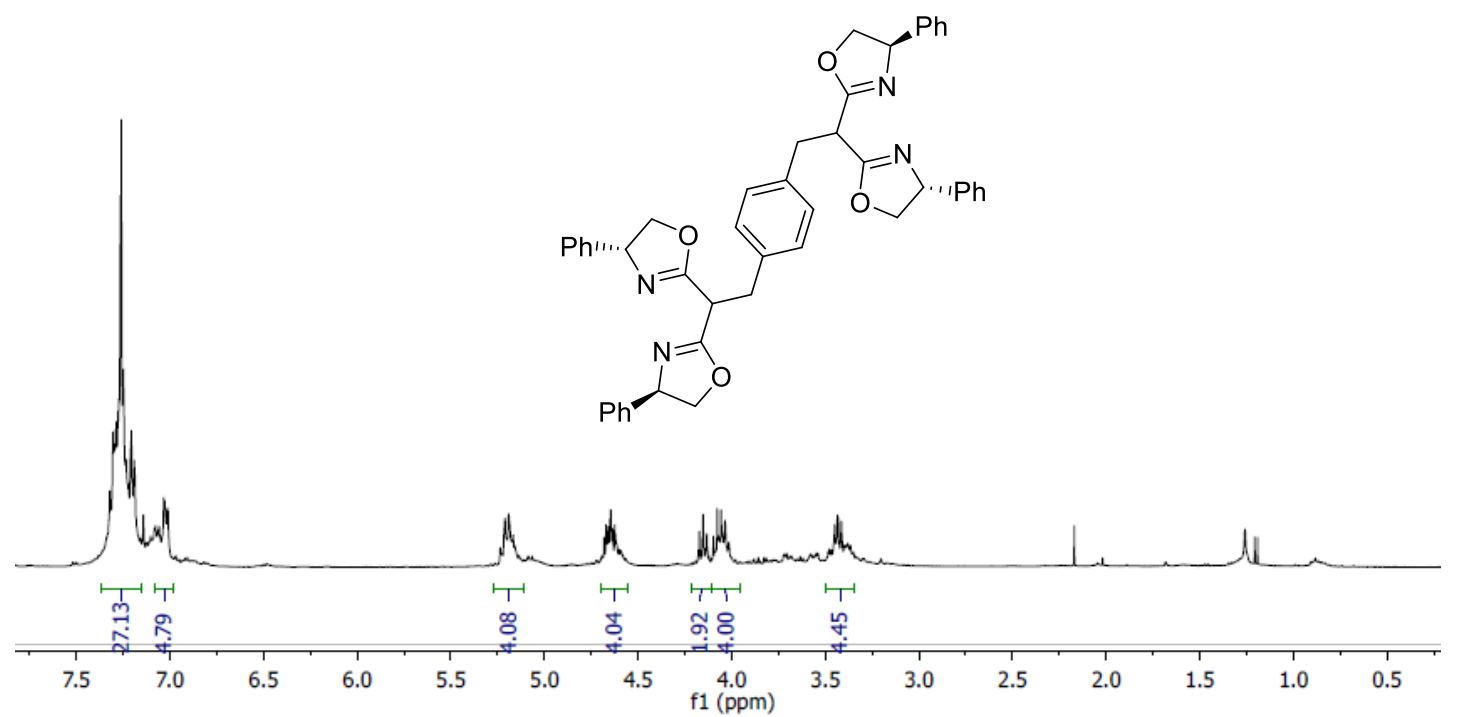

$\left(\mathrm{CDCl}_{3}, \delta \mathrm{ppm}, 400 \mathrm{MHz}\right) 7.10(\mathrm{~s}, 4 \mathrm{H}), 4.28-4.06(\mathrm{~m}, 4 \mathrm{H}), 4.01-3.79(\mathrm{~m}, 8 \mathrm{H}), 3.76-3.63(\mathrm{~m}, 2 \mathrm{H}), 3.25-3.05(\mathrm{~m}, 4 \mathrm{H})$, $1.79-155(\mathrm{~m}, 4 \mathrm{H}), 0.89(\mathrm{~d}, 6 \mathrm{H}, \mathrm{J}=6.8 \mathrm{~Hz}), 0.82(\mathrm{~d}, 6 \mathrm{H}, \mathrm{J}=6.8 \mathrm{~Hz}), 0.81(\mathrm{~d}, 6 \mathrm{H}, \mathrm{J}=6.8 \mathrm{~Hz}), 0.75(\mathrm{~d}, 6 \mathrm{H}, \mathrm{J}=6.8 \mathrm{~Hz})$
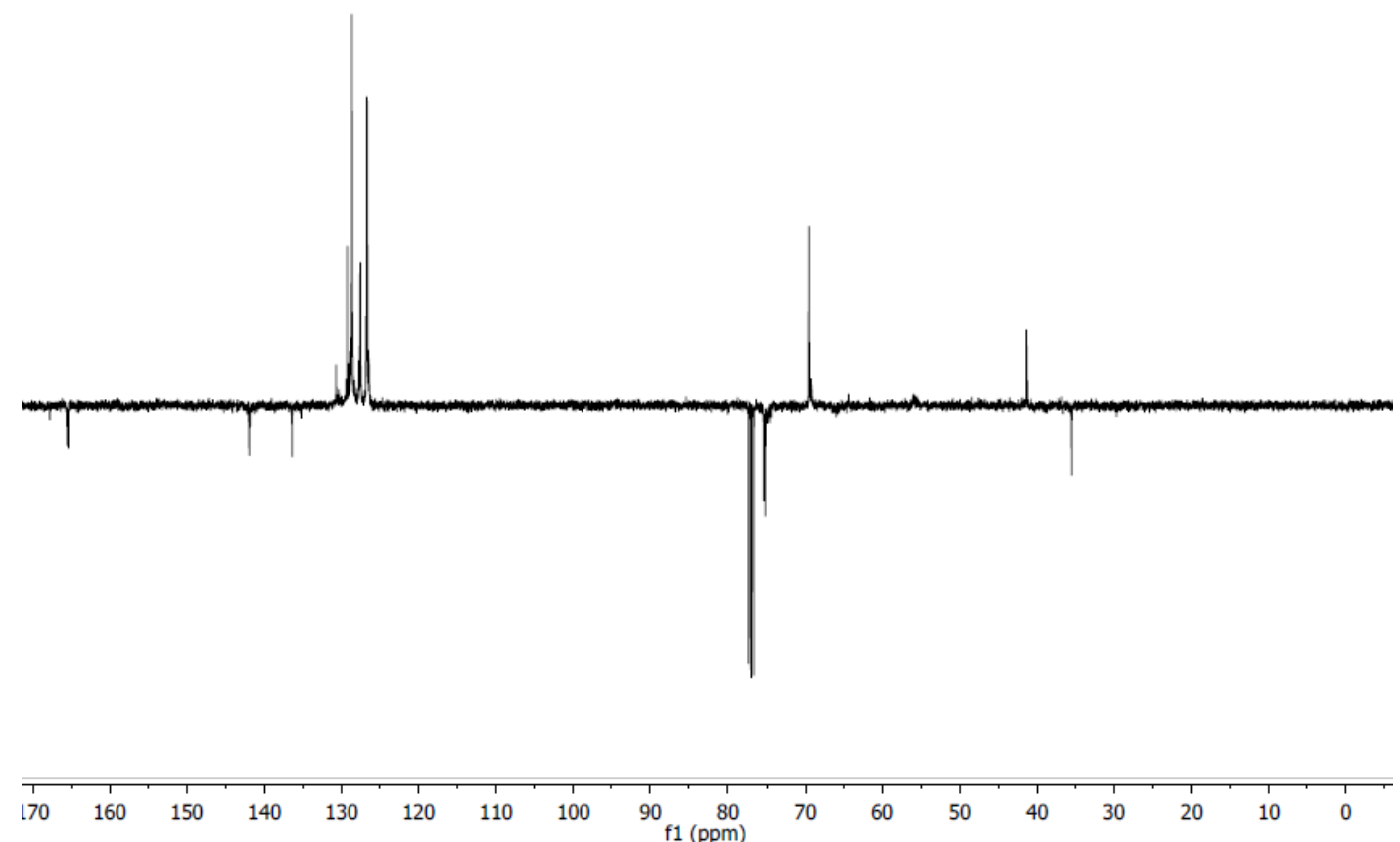

$\left(\mathrm{CDCl}_{3}, \delta \mathrm{ppm}, 100 \mathrm{MHz}\right) 164.0,163.9,136.4,128.9,71.82,71.81,70.05,70.04,41.3,35.4,32.3,32.2,18.6,18.5,17.8,17.7$ 


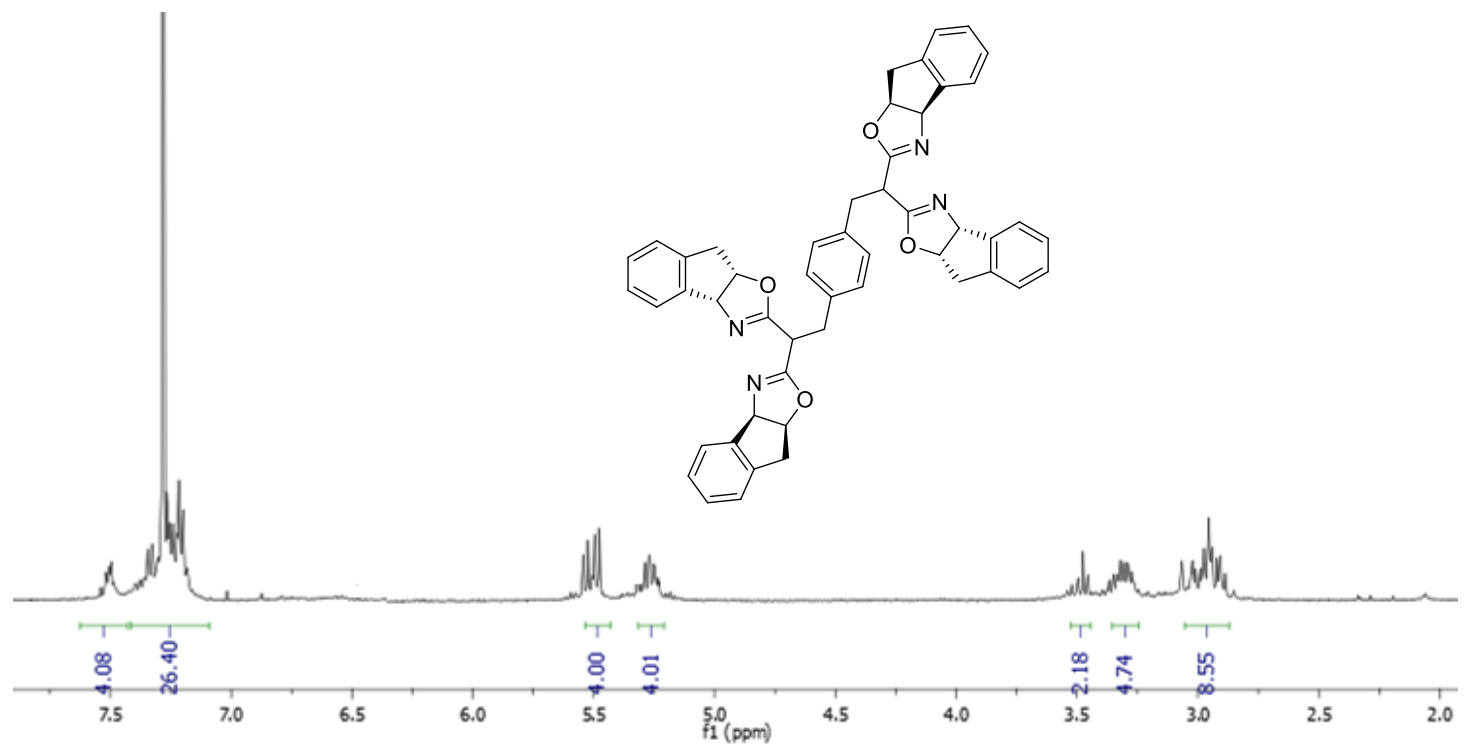

$\left(\mathrm{CDCl}_{3}, \delta\right.$ ppm, $\left.400 \mathrm{MHz}\right): 7.50-7.45(\mathrm{~m}, 2 \mathrm{H}), 7.40-7.15(\mathrm{~m}, 18 \mathrm{H}), 5.51(\mathrm{~d}, \mathrm{~J}=7.8,2 \mathrm{H}), 5.47(\mathrm{~d}, \mathrm{~J}=7.6,2 \mathrm{H}), 5.29-5.21(\mathrm{~m}$, $4 \mathrm{H}), 3.46(\mathrm{t}, \mathrm{J}=8.4,2 \mathrm{H}), 3.35-3.25(\mathrm{~m}, 4 \mathrm{H}), 3.05-2.87(\mathrm{~m}, 8 \mathrm{H})$

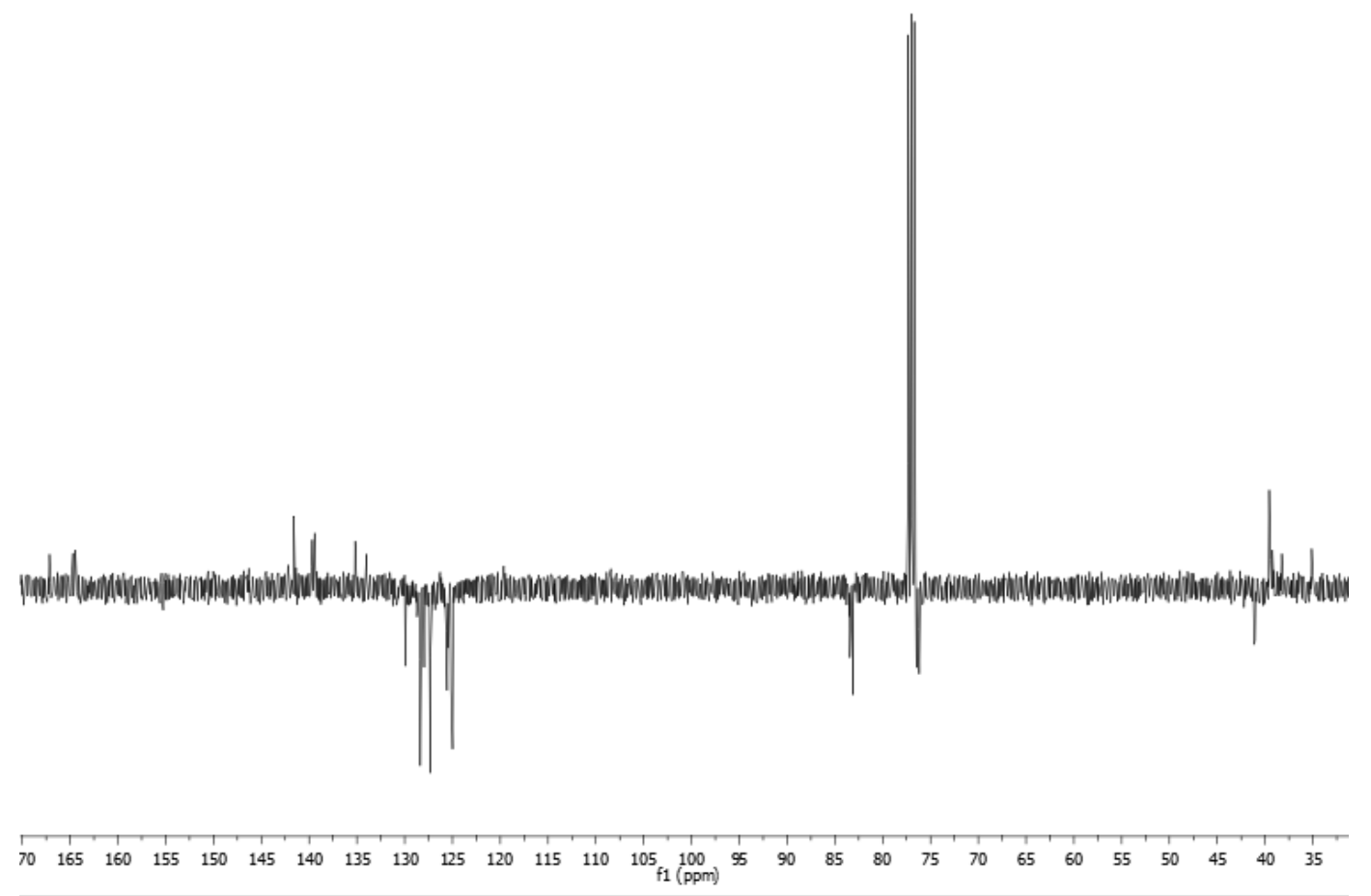

$\left(\mathrm{CDCl}_{3}, \delta \mathrm{ppm}, 100 \mathrm{MHz}\right): 167.2,164.8,164.5,164.4,141.6,139.8,139.7,139.5,135.3,135.2,134.0,129.9,128.4,128.3$, $128.0,127.5,127.3,125.6,125.5,125.2,125.0,83.4,83.1,76.4,76.3,76.2,41.2,41.1,39.6,39.5,39.2,38.3,35.1,29.7$ 


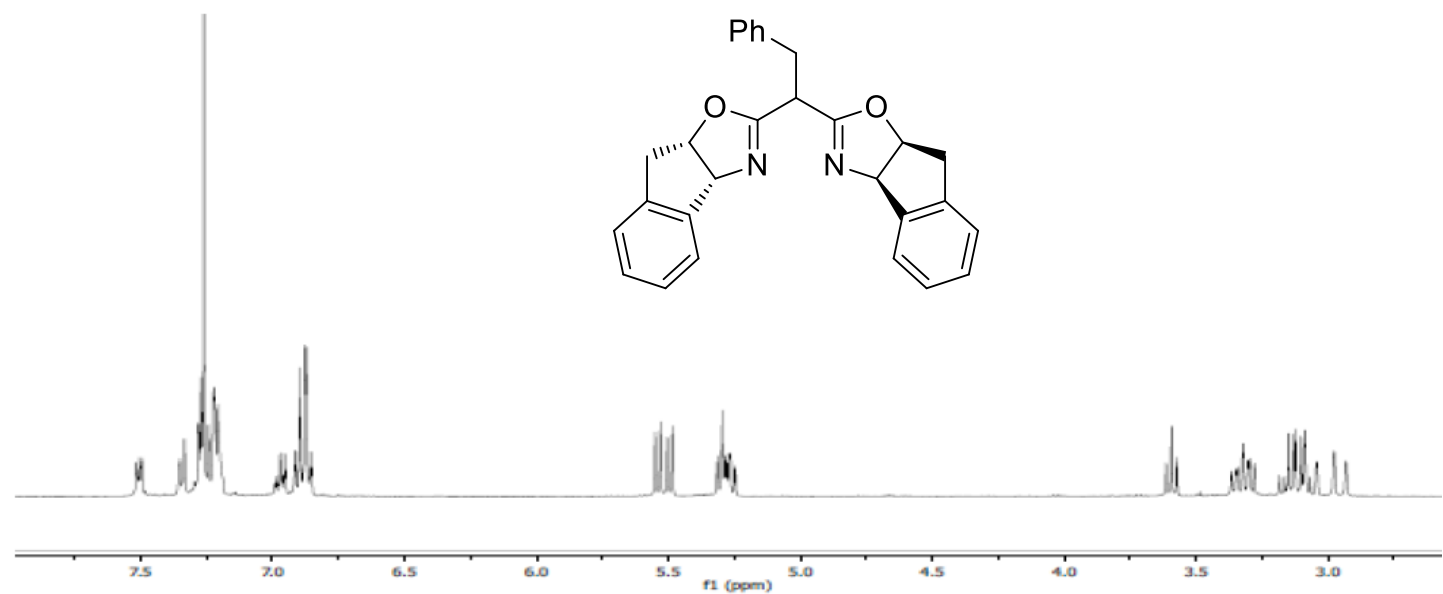

( $\mathrm{CDCl}_{3}, \delta$ ppm, 400MHz): 7.52-7.50 (m, 1H), 7.35-7.20 (m, 7H), 6.99-6.85 (m, 5H), $554(\mathrm{~d}, J=8,1 \mathrm{H}), 5.50(\mathrm{~d}, J=7.6,1 \mathrm{H})$, $5.32-5.24$ (m, 2H), 3.59 (t, $J=8.4,1 \mathrm{H}), 3.33(\mathrm{dd}, J 1=9.6, J 2=18,1 \mathrm{H}), 3.31$ (dd, $J 1=10, J 2=18,1 \mathrm{H}), 3.18-2.93$ (m, 4H).

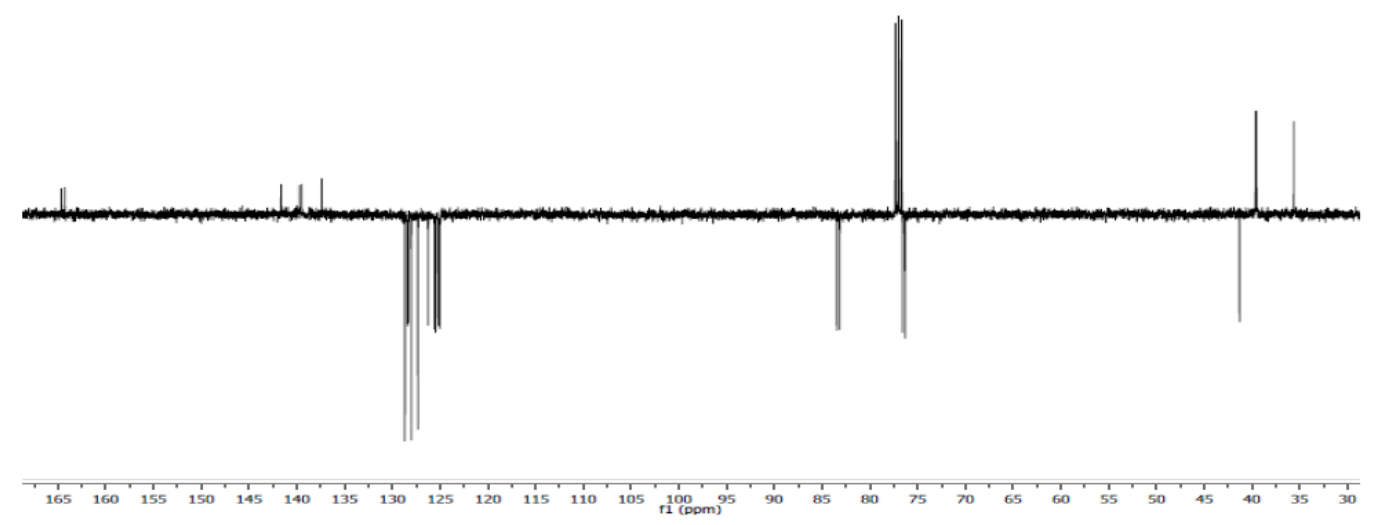

$\left(\mathrm{CDCl}_{3}, \delta\right.$ ppm, $\left.100 \mathrm{MHz}\right): 164.7,164.3,141.6,141.6 ; 139.7,139.5,137.4,128.7,128.4,128,3 ; 128,0 ; 127,3 ; 126,3 ; 125,6$; 125,$5 ; 125,2 ; 125,1 ; 83,5 ; 83,2 ; 76,6 ; 76.3,41.3,39.6,39.5,35.6$. 


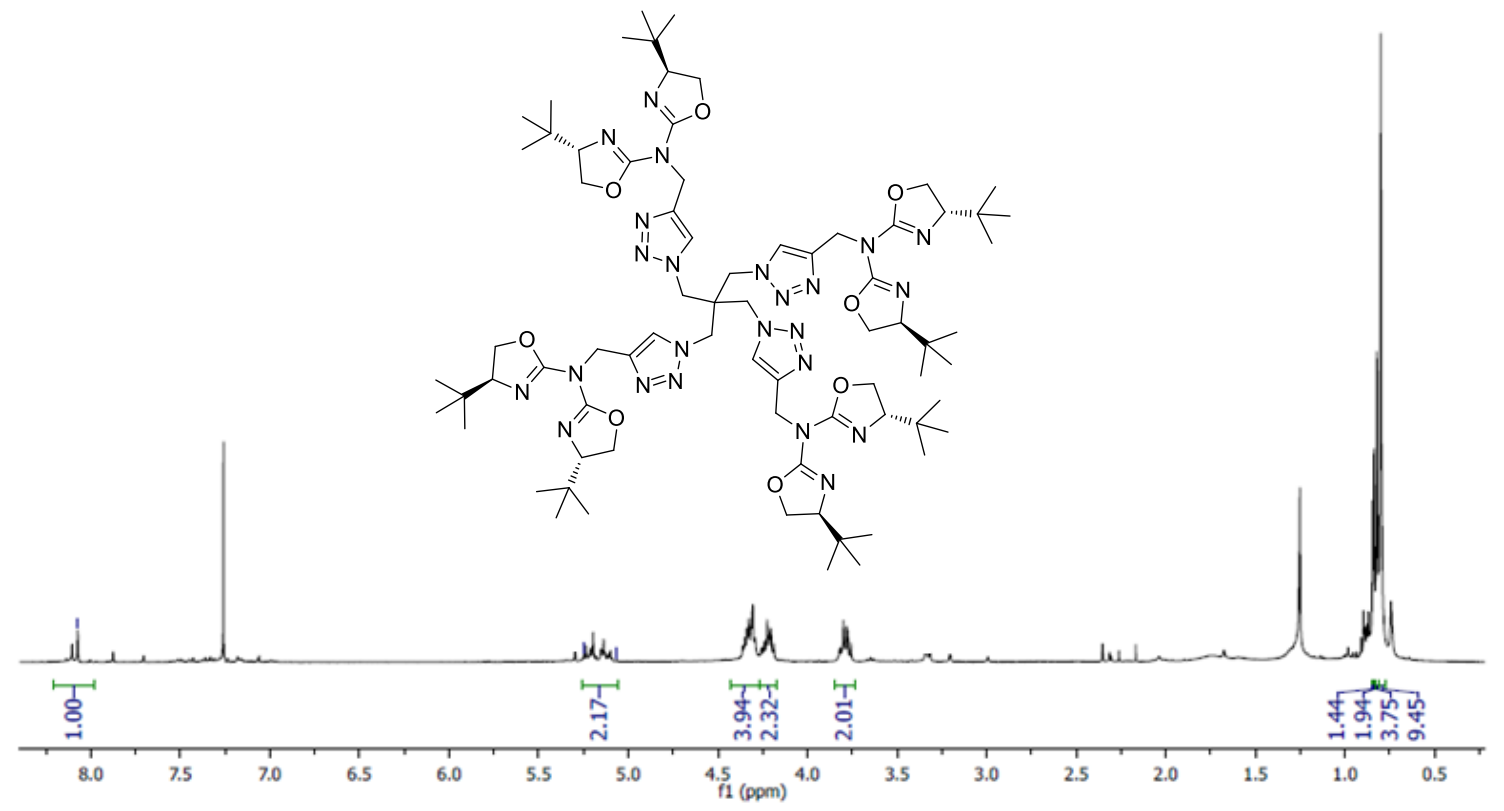

$\left(\mathrm{CDCl}_{3}, \delta \mathrm{ppm}, 400 \mathrm{MHz}\right): 8.10-8.07(\mathrm{~m}, 4 \mathrm{H}), 5.23-5.10(\mathrm{~m}, 8 \mathrm{H}), 4.36-4.29(\mathrm{~m}, 16 \mathrm{H}), 4.25-4.19(\mathrm{~m}, 8 \mathrm{H}), 3.82-3.76(\mathrm{~m}$, $8 \mathrm{H}), 0.85-0.80(\mathrm{~m}, 72 \mathrm{H})$

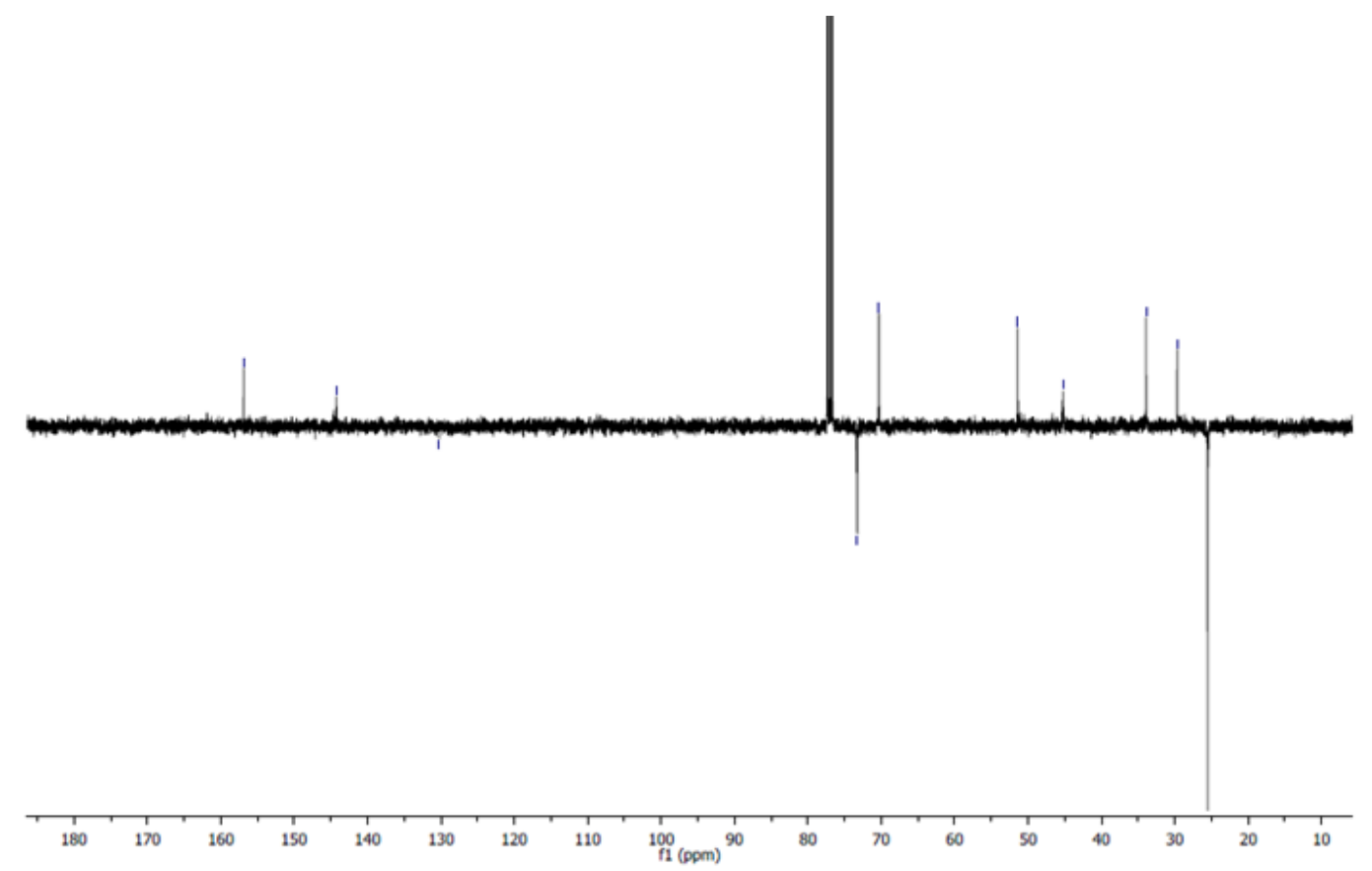

$\left(\mathrm{CDCl}_{3}, \delta \mathrm{ppm}, 100 \mathrm{MHz}\right): 156.9,144.2,130.2,73.2,70.3,51.4,45.2,33.9,29.7,255$ 


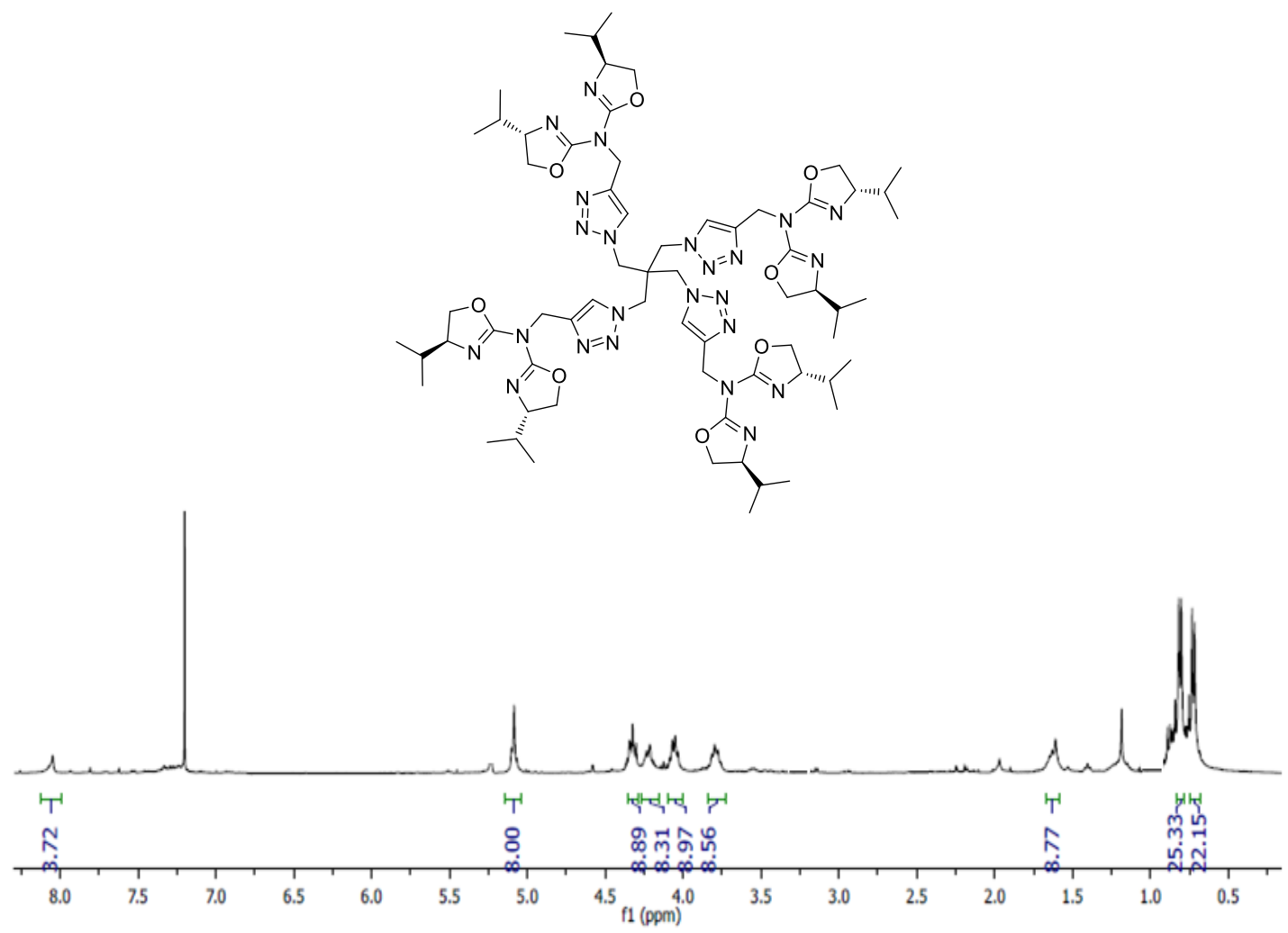

$\left(\mathrm{CDCl}_{3}, \delta \mathrm{ppm}, 400 \mathrm{MHz}\right): 8.16-8.08(\mathrm{~m}, 4 \mathrm{H}), 5.19-5.11(\mathrm{~m}, 8 \mathrm{H}), 4.44-4.34(\mathrm{~m}, 8 \mathrm{H}), 4.32-4.23(\mathrm{~m}, 8 \mathrm{H}), 4.16-4.06(\mathrm{~m}, 8 \mathrm{H})$, $3.90-3.78(\mathrm{~m}, 8 \mathrm{H}), 1.77-1.61(\mathrm{~m}, 8 \mathrm{H}), 0.87(\mathrm{~d}, 24 \mathrm{H}, J=6.7 \mathrm{~Hz}), 0.78(\mathrm{~d}, 24 \mathrm{H}, J=6.8 \mathrm{~Hz})$.

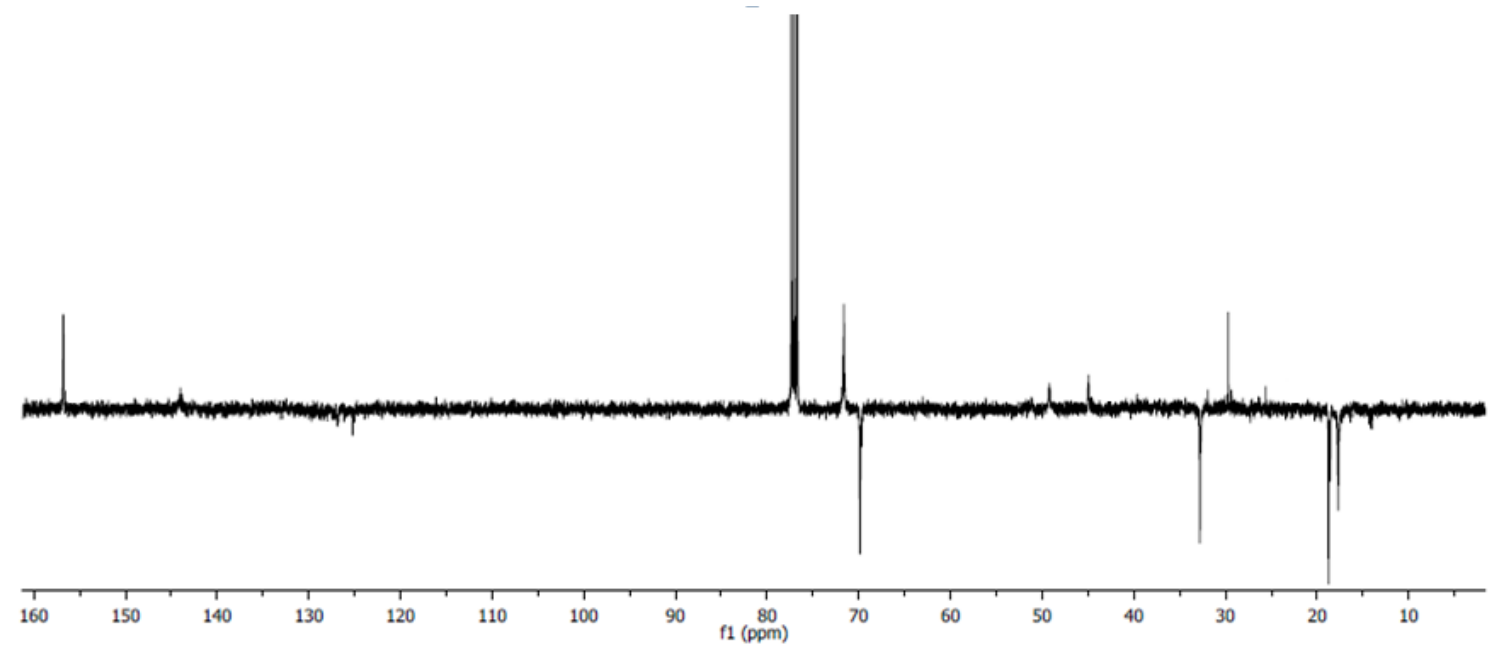

$\left(\mathrm{CDCl}_{3}, \delta \mathrm{ppm}, 100 \mathrm{MHz}\right): 156.7,144.0,127.9,71.6,69.8,49.1,44.9,32.7,29.6,18.7,17.7$ 


\section{Gas chromatography analyses of the Cyclopropanation reaction of styrene with ethyl diazoacetate}

\subsection{Yield}

FID from Hewlett-Packard 5890-II, cross-linked methyl silicone column (SPB): $25 \mathrm{~m} \times 0.2 \mathrm{~mm} \times 0.33 \mu \mathrm{m}$; helium as carrier gas. 20 psi; injector temperature: $230{ }^{\circ} \mathrm{C}$; detector temperature: $250{ }^{\circ} \mathrm{C}$; oven program: $70{ }^{\circ} \mathrm{C}(3 \mathrm{~min}), 15^{\circ} \mathrm{C} \mathrm{min}{ }^{-1}$ to $200{ }^{\circ} \mathrm{C}$ $(5 \mathrm{~min})$; retention times: ethyl diazoacetate $3.2 \mathrm{~min}$, styrene $3.5 \mathrm{~min}, n$-decane $5.1 \mathrm{~min}$, diethylmaleate $7.4 \mathrm{~min}$, diethyl fumarate $7.6 \mathrm{~min}$, cis cyclopropanes $10.5 \mathrm{~min}$, trans cyclopropanes $11.0 \mathrm{~min}$.

In order to determine the cyclopropanation yield $n$-decane is used as internal standard. A calibration curve was done previously in the group to calibrate the FID response of the products.

$$
\% \text { Yield }=0.8153 \frac{\text { decane } \mathrm{mmol} \cdot \text { cyclopropanes area }}{\text { diazoacetate } \mathrm{mmol} \cdot \text { decane area }} \cdot 100
$$

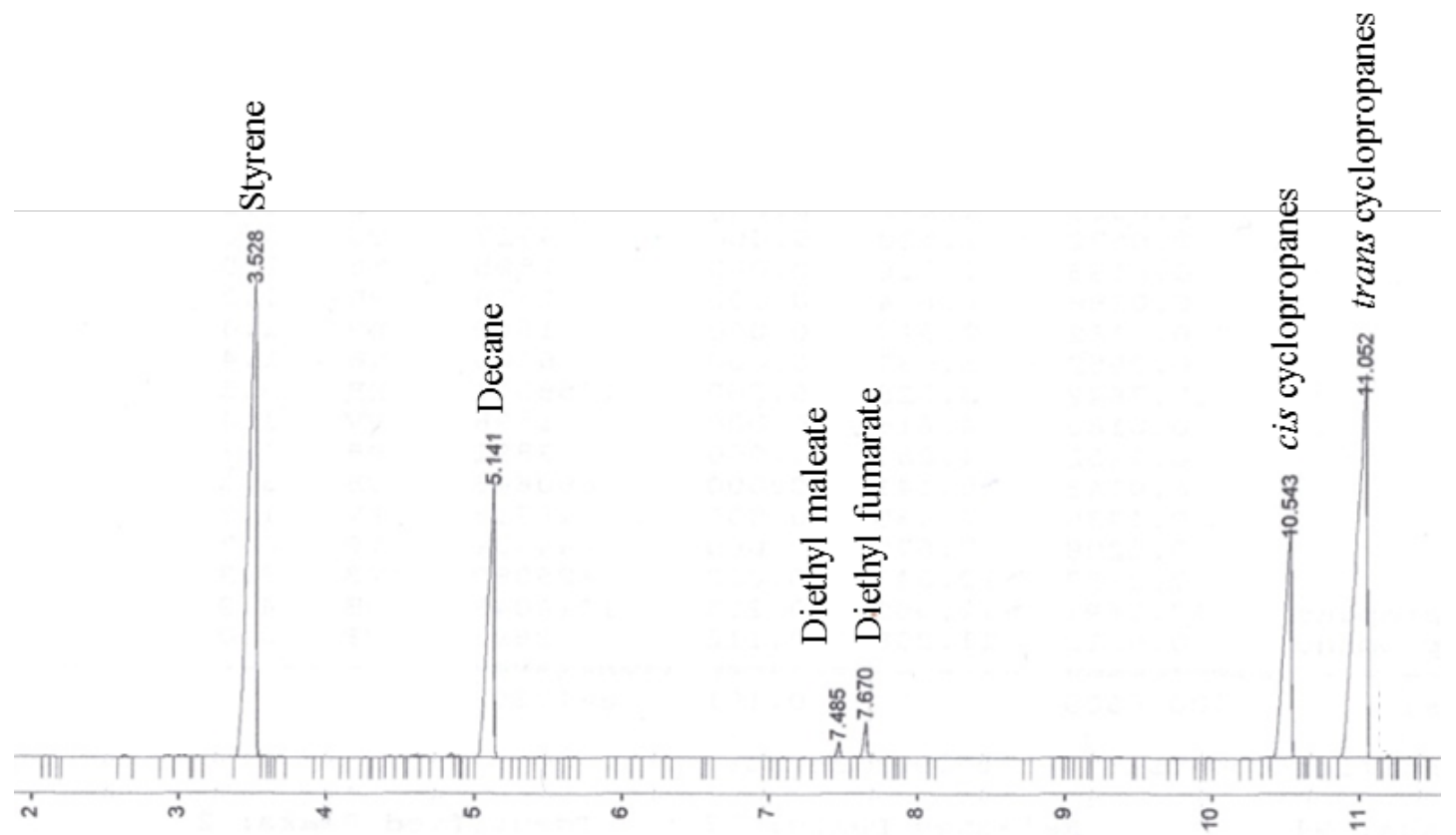

Typical CG chromatogram for the cyclopropanation reaction of styrene and ethyl diazoacetate. 


\subsection{Enantioselectivity}

The enantioselectivities of the reactions were also determined by gas chromatography: FID from Hewlett-Packard 5890-II, Cyclodex- $\beta$ column: $30 \mathrm{~m} \times 0,25 \mathrm{~mm} \times 0,25 \mu \mathrm{m}$; helium as carrier gas. $20 \mathrm{psi}$; injector temperature: $230{ }^{\circ} \mathrm{C}$; detector temperature: $250{ }^{\circ} \mathrm{C}$; oven temperature program: $120^{\circ} \mathrm{C}$ isotherm; retention times: $(1 S, 2 R)$-cyclopropane $39.6 \mathrm{~min},(1 R, 2 S)$ cyclopropane $40.6 \mathrm{~min},(1 R, 2 R)$-cyclopropane $48.3 \mathrm{~min},(1 S, 2 S)$-cyclopropane $48.9 \mathrm{~min}$.

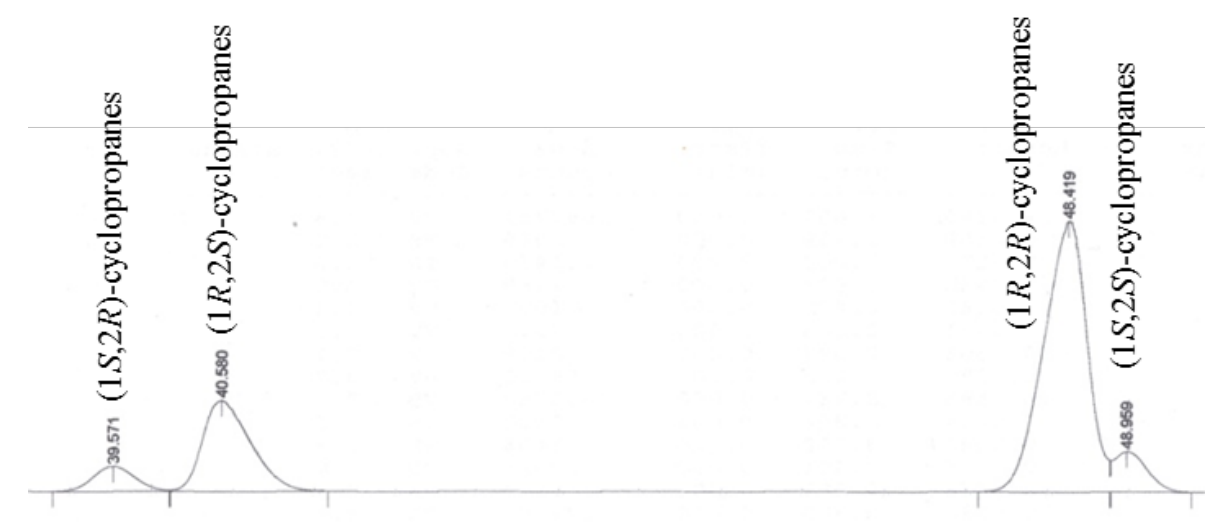

Typical chiral CG chromatogram for the cyclopropanation reaction of styrene and ethyl diazoacetate. 